\title{
Understanding the reactivity of Mn-oxo porphyrins for substrate hydroxylation: theoretical predictions and experimental evidence reconciled
}

Damiano Ricciarelli, ${ }^{a}$ Quan Manh Phung, ${ }^{b c}$ Leonardo Belpassi ${ }^{d e}$, Jeremy N. Harvey ${ }^{{ }^{*}}$ 'Paola Belanzoni ${ }^{\text {ade* }}$

${ }^{a}$ Department of Chemistry, Biology and Biotechnology, University of Perugia, via Elce di Sotto 8, 06123 Perugia, Italy E-mail: paola.belanzoni@unipg.it

${ }^{b}$ Department of Chemistry, KU Leuven, Celestijnenlaan 200F, B-3001 Leuven, Belgium E-mail: jeremy.harvey@kuleuven.be

${ }^{c}$ Institute of Transformative Bio-Molecules (WPI-ITbM), Nagoya University, Chikusa, Nagoya 464-8602, Japan

${ }^{d}$ Institute of Molecular Science and Technologies (CNR - ISTM), clo Department of Chemistry, Biology and Biotechnology, University of Perugia, via Elce di Sotto 8, 06123 Perugia, Italy

${ }^{e}$ Consortium for Computational Molecular and Materials Sciences (CMS) ${ }^{2}$, via Elce di Sotto 8, 06123 Perugia, Italy

\begin{abstract}
The Mn-oxo porphyrin (MnOP) mechanism for substrate hydroxylation is computationally studied with the aim to better understand reactivity in these systems. Theoretical studies suggest Mn(V)OP species as very reactive intermediates with thermally accessible reaction barriers represented by low spin/high spin crossover occurring in the $\mathrm{Mn}(\mathrm{V}) \mathrm{OP}$ oxidant, and kinetics for selected $\mathrm{Mn}(\mathrm{V}) \mathrm{OP}$ species indeed find high reactivity. On the other hand, MnOP complexes lead to low yields in catalytic hydroxylation reactions of several different substrates, suggesting low rate constants and high reaction barriers. The origin of this inconsistency is very important to understand the reactivity of Mn-oxo porphyrins and to improve the catalytic conditions. In this work we use the toluene hydroxylation by $\mathrm{Mn}(\mathrm{V}) \mathrm{OP}\left(\mathrm{H}_{2} \mathrm{O}\right)^{+}$complex as a case study to gain deep insight into the reaction mechanism and to check that it should indeed have high reactivity. Minimum energy crossing point (MECP) results on $\mathrm{H}$-abstraction process from toluene indicate a first crossover from a singlet to a triplet spin state of the $\mathrm{Mn}(\mathrm{V}) \mathrm{OP}\left(\mathrm{H}_{2} \mathrm{O}\right)^{+}$species, which represents the rate-determining step with a thermally accessible barrier, followed by a very facile H-abstraction by the triplet complex. Issues concerning i) the validation of the level of the DFT theory employed (BP86) to describe the singlettriplet energy gap in the $\mathrm{Mn}(\mathrm{V}) \mathrm{OP}\left(\mathrm{H}_{2} \mathrm{O}\right)^{+}$system vs. highly accurate DMRG-CASPT2/CC calculations and ii) the influence of the axial ligand ( $\mathrm{X}=$ none, $\mathrm{Cl}^{-}, \mathrm{CH}_{3} \mathrm{CN}, \mathrm{OH}^{-}$and $\left.\mathrm{O}^{2-}\right)$ on $\mathrm{MnOP}$ reactivity, which models the different experimental conditions, are addressed. The ligand trans
\end{abstract}


influence mainly controls the reactivity through the singlet-triplet energy gap modulation, with the porphyrin ruffling distortion also finely tuning it. Finally, a stepwise model for the $\mathrm{H}$-abstraction process is proposed which allows a direct comparison between the calculated and experimentally measured Gibbs free activation energy barriers (R. Zhang, J.H. Horner, M. Newcomb J. Am. Chem. Soc. $2005,127,6573-6582)$. The low yields in catalysis are shown not to be due to low reactivity of $\mathrm{Mn}(\mathrm{V})$.

\section{Introduction}

Despite the large body of literature on the reactivity of Mn-oxo porphyrins (MnOP) complexes, ${ }^{1-12}$ $2,3,4,6,7,8,9,10,11,12$ there is still a conundrum to be solved. It clearly emerges when one compares various theoretical and experimental results concerning the reactivity of Mn-oxo porphyrins for substrate hydroxylation. Synthetic biomimetic systems based on Mn-porphyrins ${ }^{13,14}$ have been shown to be catalysts for the hydroxylation and epoxidation of a wide range of organic substrates. A very important goal to improve the catalytic conditions of such MnOP-mediated hydroxylation reactions is to gain a higher level of understanding of the mechanisms involved.

From the experimental side, reactive $\mathrm{Mn}(\mathrm{V}) \mathrm{OP}$ complexes were first generated at ambient temperature in water and spectroscopically characterized by Groves and co-workers. ${ }^{15,16}$ These species were found to unambiguously adopt a singlet ground state. On the basis of reactivity studies, Jin and Groves ${ }^{16}$ proposed that release of oxygen from $\mathrm{Mn}(\mathrm{V}) \mathrm{OP}^{+}$should proceed via a thermally accessible reactive high-spin (triplet or quintet) state. Subsequently, Nam and co-workers ${ }^{17,18}$ and Newcomb and co-workers ${ }^{19,20}$ extended Groves' pioneering work. Nam and co-workers showed experimentally that the singlet state of $[\mathrm{MnO}(\operatorname{tdcpp})]^{+}(\operatorname{tcdpp}=$ tetra-(2,6-dichlorophenyl)-porphyrin) was not capable of oxygenating alkanes and thus active species were predicted to be probably high spin. These findings suggested that the concept of two-state reactivity could be applied also to $\mathrm{Mn}(\mathrm{V}) \mathrm{OP}$ species, analogously to iron-oxo species. ${ }^{21}$ The authors also reported that manganese(V)oxo porphyrins associated with terminal oxidants, such as PhIO, afforded relatively high product yields in the oxygenation of olefins (36-24\%) and somewhat lower yields in the oxygenation of alkanes (10-16\%), where equimolar amounts of alcohol and ketone products were observed. Such low product yields in the hydroxylation reactions These findings suggested that the concept of twostate reactivity could be applied also to $\mathrm{Mn}(\mathrm{V}) \mathrm{OP}$ species, analogously to iron-oxo species. ${ }^{22}$ and the prediction that a singlet ground state and thermally accessible higher spin states are likely involved 
in the reaction with $\mathrm{MnOP}$ complexes are inconsistent. However, as we will show in the present work, this prediction is a key element of the solution of the conundrum.

Newcomb and co-workers ${ }^{20}$ generated porphyrin-manganese(V)-oxo species from the corresponding manganese (III) perchlorate salts via laser flash photolysis (LFP), detecting the highly reactive Mnoxo intermediates in organic solvents and performing direct kinetic studies of their reactions with typical organic substrates (cis-stilbene, $\mathrm{Ph}_{2} \mathrm{CH}_{2}, \mathrm{PhEt}$, and $\mathrm{PhEt}-\mathrm{d}_{10}$ ). Three different porphyrins in the Mn-oxo complexes, namely 5,10,15,20-tetraphenylporphyrin (TPP), 5,10,15,20tetrakis(pentafluorophenyl)porphyrin (TPFPP) and 5,10,15,20-tetrakis(4methylpyridinium)porphyrin (TMPyP), were employed. Reactions of $\mathrm{Mn}(\mathrm{V}) \mathrm{OP}$ with the substrates are complicated because of the simultaneous presence under reaction conditions of $\mathrm{Mn}(\mathrm{III}), \mathrm{Mn}(\mathrm{IV})$ and $\mathrm{Mv}(\mathrm{V})$ species. indicated no formation of $\mathrm{Mn}(\mathrm{IV}) \mathrm{OP}$ and velocities of comproportionation reactions of $\mathrm{Mn}(\mathrm{V}) \mathrm{OP}$ with the $\mathrm{Mn}(\mathrm{III}) \mathrm{P}$ products from the oxidation of substrate smaller than the velocities of the reactions of $\mathrm{Mn}(\mathrm{V}) \mathrm{OP}$ with substrate. "Apparent" rate constants for reactions of $\mathrm{Mn}(\mathrm{IV}) \mathrm{OP}$ derivatives, produced photochemically from the corresponding manganese(III) chlorate salts, showed that these intermediates react very fast (with nearly a diffusion-controlled rate constant) via disproportionation to give $\mathrm{Mn}(\mathrm{V}) \mathrm{OP}$ and $\mathrm{Mn}(\mathrm{III}) \mathrm{XP}$ species, where $\mathrm{X}$ could be one of the counterions present in the photolysis conditions $\left(\mathrm{Cl}^{-}, \mathrm{ClO}_{4}^{-}, \mathrm{ClO}_{3}^{-}, \mathrm{NO}_{3}^{-}\right)$or hydroxide, and that $\mathrm{Mn}(\mathrm{V}) \mathrm{OP}$ was the major, or possibly the only, active oxidant in the reactions. The $\mathrm{Mn}(\mathrm{III}) / \mathrm{Mn}(\mathrm{IV}) / \mathrm{Mn}(\mathrm{V})$ equilibrium involved in the oxidation reactions was described as: $2 \mathrm{HX}+2$ $\mathrm{Mn}(\mathrm{IV}) \mathrm{OP} \rightleftharpoons(\mathrm{Mn}(\mathrm{V}) \mathrm{OP})^{+}+\mathrm{Mn}(\mathrm{III}) \mathrm{XP}+\mathrm{H}_{2} \mathrm{O}+\mathrm{X}^{-}$. and the authors provided evidence that the velocities of disproportionation and comproportionation reactions can readily exceed the velocities of substrate oxidations. The apparent equilibrium constant values for the disproportionation reactions of $\mathrm{Mn}(\mathrm{IV}) \mathrm{OP}$ in $\mathrm{CH}_{3} \mathrm{CN}$ as solvent indicated that little of the highly reactive $\mathrm{Mn}(\mathrm{V}) \mathrm{OP}$ species would be present in a catalytic reaction. The reactivity patterns determined from LFP studies of (TPFPP)Mn(V)O were also reproduced in the catalytic reactions using mcpba (metachloroperbenzoic acid) or iodosobenzene as sacrificial oxidant. The equilibrium between $\mathrm{Mn}(\mathrm{III}) / \mathrm{Mn}(\mathrm{IV}) / \mathrm{Mn}(\mathrm{V})$ species involved in the reaction was observed to serve to sequester much of the potential catalyst as unreactive Mn(IV)OP. Interestingly, in the Mn(IV)OP case, the measured rate constants for the formation of oxidized products could be apparent and much lower than the true rate constants for reaction of the active oxidants with substrates.

Later work by Groves and co-workers ${ }^{23}$ found strongly $\mathrm{pH}$ dependent O-transfer reactivity for $\mathrm{Mn}(\mathrm{V}) \mathrm{O}$ TMP (TMP=tetramesitylporphirin). At a high $\mathrm{pH}$ the oxo complex is unreactive, whereas at low $\mathrm{pH} \mathrm{O}$ transfer takes place. This behavior was associated with acid-base equilibria involving three protonation states of the $\mathrm{Mn}(\mathrm{V}) \mathrm{OP}$ system, namely $\left[\mathrm{MnOP}\left(\mathrm{H}_{2} \mathrm{O}\right)\right]^{+},[\mathrm{MnOP}(\mathrm{OH})]$ and $[\mathrm{MnOPO}]^{-}$. 
Each of these species containing a different O-bound ligand trans to the oxo group was shown to have different reactivity.

Overall, the experimental results provide a picture of an unusual reactivity pattern exhibited by these MnOP species. They derive from three main effects: the spin-state crossing, the equilibration of different oxidation state species, $\mathrm{Mn}(\mathrm{V}), \mathrm{Mn}(\mathrm{III})$ and $\mathrm{Mn}(\mathrm{IV})$, and the $\mathrm{pH}$ dependence of the processes.

Generally, for metalloporphyrin-catalyzed oxidation of substrates, the so-called Groves rebound mechanism is widely accepted. $.^{24},{ }^{25},{ }^{26}$ It consists of three steps: 1) oxidation of the $\mathrm{Mn}(\mathrm{III}) \mathrm{P}$ ( $\mathrm{P}=$ porphyrin) catalyst to $\mathrm{Mn}(\mathrm{V}) \mathrm{OP}$ oxo intermediate; 2$) \mathrm{H}$ atom abstraction from the substrate $\mathrm{C}-\mathrm{H}$ bond, leading to an organic radical and a Mn(IV)OHP hydroxo intermediate; and 3) OH-rebound by $\mathrm{OH}$ transfer to the organic radical. The rate-determining step (RDS) is the H-abstraction step and the key intermediate is the $\mathrm{Mn}(\mathrm{V}) \mathrm{OP}$ oxo species.

A combined experimental/theoretical work by Brudvig, Crabtree, Eisenstein and co-workers ${ }^{12}$ showed that a postulated Mn-oxo active species, $[\mathrm{Mn}(\mathrm{O})(\mathrm{tpp})(\mathrm{Cl})](\mathrm{tpp}=$ tetraphenylporphyrin), could promote the oxidation of DHP (DHP = 9,10-dihydrophenantrene) by competitive desaturation and hydroxylation pathways, which share a common initial step, radical $\mathrm{H}$ abstraction from one of the DHP $\mathrm{sp}^{3} \mathrm{C}-\mathrm{H}$ bonds, leading to a product mixture. Interestingly, under various reaction conditions (i.e. in $\mathrm{N}_{2}$ or air atmosphere, in $\mathrm{CD}_{2} \mathrm{Cl}_{2}$ or $\mathrm{CD}_{3} \mathrm{CN}$ solvents) the hydroxylation yields were always lower than the desaturation yields (11-26\% and 46-67\%, respectively in $\mathrm{N}_{2}, 9-11 \%$ and $2-31 \%$, respectively, in air).

From the theoretical side, Nam et al. experimental findings ${ }^{18}$ were examined by Eisenstein and coworkers. ${ }^{27}$ The authors carried out DFT investigations on the Groves rebound mechanism for the oxidation of toluene catalyzed by a model of $[\mathrm{MnO}(\operatorname{tdcpp})]^{+}$. In this work the singlet state of the oxo intermediate was shown not to be active, whereas the reaction could easily take place on the lowest lying triplet and quintet potential energy surfaces with very low energy barriers, in agreement with experimental results. In addition, it was demonstrated that the rebound mechanism for this reaction is favored for spin states with oxyl character.

A recent investigation on the $\mathrm{Mn}(\mathrm{V}) \mathrm{OP}^{+}$system performed by Pierloot et al. ${ }^{28}$ with correlated ab initio methods (CASPT2, RASPT2) provided an accurate description for the spin state energetics, the oxyl character of the complex and for their role in oxygen transfer reactions. Analogously, the $\mathrm{Mn}(\mathrm{V}) \mathrm{OP}^{+}$ singlet ground state was proven to lack the oxyl character and to be kinetically inert. As proposed by Jin and Groves, ${ }^{16}$ Pierloot and co-workers ${ }^{28}$ demonstrated that the oxygen transfer from $\mathrm{Mn}(\mathrm{V}) \mathrm{OP}^{+}$ should proceed via a thermally accessible reactive high spin state (triplet or quintet) which provides sufficient oxyl character to the system for reacting. In particular, the triplet state has been shown to 
correspond to the excitation of an electron from a non-bonding $\mathrm{Mn} 3 \mathrm{~d}_{\mathrm{xy}}$ orbital to one of the $\mathrm{Mn}=\mathrm{O}$ $\pi^{*}$ orbitals, thus giving rise to a certain amount of oxyl character.

Importantly, by the RASPT2 analysis it was also shown that in a density functional theory framework pure functionals have to be preferred over hybrid ones, since for these systems hybrid functionals yield less accurate energies and are extremely dependent on the contribution of exact exchange and hence, inadequate for quantitative reaction mechanism studies.

On the basis of Groves and co-workers' experimental results, ${ }^{23}$ Groves and co-workers ${ }^{29}$ and Eisenstein and co-workers ${ }^{30}$ theoretically investigated the reactivity of $\mathrm{Mn}(\mathrm{V}) \mathrm{OP}$ species. These investigations both rationalized the fact that, experimentally, these compounds are less reactive under basic than under acidic conditions and provided a new perspective about Mn-oxo porphyrin reactivity based on the finding that the larger the low spin/high spin energy gap the less reactive the compound. In particular, the reactivity of the isomeric $\mathrm{Mn}(\mathrm{V}) \mathrm{O}(2-\mathrm{TMPyP})$ and $\mathrm{Mn}(\mathrm{V}) \mathrm{O}(4-\mathrm{TMPyP})$ (2-TMPyP $=2$-tetra-N-methylpyridyl; 4-TMPyP = 2-tetra-N-methylpyridyl) species was investigated and results showed that both the basicity of the oxo ligand (proton affinity) and the low spin-high spin electronpromotion energy effects contribute to modulate their reactivity. ${ }^{29}$ The $\mathrm{H}$-abstraction process for the three protonation states of $\mathrm{Mn}(\mathrm{V}) \mathrm{OP}$, namely $\left[\mathrm{MnOP}\left(\mathrm{H}_{2} \mathrm{O}\right)\right]^{+},[\mathrm{MnOP}(\mathrm{OH})]$ and $[\mathrm{MnOPO}]^{-}$, was studied, confirming that the lowest trans-influence ligand, $\mathrm{H}_{2} \mathrm{O}$, gives the most reactive complex. ${ }^{30}$ The reactivity was found to increase along the series in the order $\mathrm{O}^{2-}<\mathrm{OH}^{-}<\mathrm{H}_{2} \mathrm{O}$, in agreement with the experimentally observed $\mathrm{pH}$ effect on MnOP reactivity. ${ }^{23}$ Generally, the theoretical results point out that in the $\mathrm{Mn}(\mathrm{V}) \mathrm{OP}$-catalyzed hydroxylation reaction mechanism the rate-determiningstep is the H-abstraction step and that a reasonable activation barrier is the spin-crossover, characterized as an instantaneous transition from a singlet to a thermally accessible triplet spin state of the $\mathrm{Mn}(\mathrm{V}) \mathrm{OP}$ complex before it reacts. In this framework, these $\mathrm{Mn}(\mathrm{V}) \mathrm{OP}$ species are depicted as good candidates for substrate oxidations even at thermal conditions and the free energy barrier was estimated roughly as 10-15 kcal/mol. ${ }^{27}$ However, in the work of Brudvig, Crabtree, Eisenstein and co-workers, ${ }^{12}$ as well as in Nam and co-workers experiments, ${ }^{18}$ the yield of hydroxylated product is inconsistently low. These experimental data might suggest that the hydroxylation rate constant is low and thus the rate determining step free energy barrier is very high, in clear contradiction to theoretical results. We should note that the solution conditions in which these kinetics were carried out are quite complicated, since many equilibria could be involved. First of all the Mn species, inside the pot, show different oxidation states ( $\mathrm{Mn}(\mathrm{III}), \mathrm{Mn}(\mathrm{IV}), \mathrm{Mn}(\mathrm{V})$ porphyrin complexes are present) which can have different oxidation powers, as observed in Newcomb and co-workers work. ${ }^{20}$

Thus, the question arises as to how to reconcile the computational picture of $\mathrm{Mn}(\mathrm{V}) \mathrm{OP}$ species as very reactive intermediates, with thermally accessible spin-crossover reaction barriers, with the 
experimental evidence that MnOP complexes show very low yields in hydroxylation reactions, implying low rate constants and high reaction barriers.

The resolution of this conundrum is very important to improve the catalytic conditions and it certainly deserves further studies. This is the aim of this work. Here, we use toluene hydroxylation by $\mathrm{Mn}(\mathrm{V}) \mathrm{OP}\left(\mathrm{H}_{2} \mathrm{O}\right)^{+}$complex to gain a deep insight into the reaction mechanism and to provide a rationale of Newcomb and co-workers experimental data. ${ }^{20}$ Based on their fundamental kinetic studies, in our analysis we will focus only on the $\mathrm{Mn}(\mathrm{V})$ species since, although the $\mathrm{Mn}(\mathrm{V}) \mathrm{OP}$ intermediate is actually not highly concentrated in a catalytic reaction and is present in equilibrium with $\mathrm{Mn}(\mathrm{III})$ and $\mathrm{Mn}(\mathrm{IV})$ species, it is considered as the only active oxidant. The H-abstraction from toluene by $\mathrm{Mn}(\mathrm{V}) \mathrm{OP}\left(\mathrm{H}_{2} \mathrm{O}\right)^{+}$is depicted in Scheme 1. In this spin-forbidden process the spin state changes from singlet in the reactants to triplet in the products. Firstly, the reaction profile is calculated using the minimum energy crossing point (MECP) approach which suggests that the process should occur through a preliminary spin-crossover in the $\mathrm{Mn}(\mathrm{V}) \mathrm{OP}\left(\mathrm{H}_{2} \mathrm{O}\right)^{+}$complex from singlet to triplet and a subsequent $\mathrm{H}$-abstraction from toluene with a very low activation barrier, in agreement with literature theoretical studies. Then, the singlet-triplet energy gap for the $\mathrm{Mn}(\mathrm{V}) \mathrm{OP}\left(\mathrm{H}_{2} \mathrm{O}\right)^{+}$complex is calculated at the DFT/BP86 level of theory and a validation of the employed functional against the high-level correlated DMRG-CASPT2/CC method ${ }^{31}$ is performed to estimate the error bars of our results. DFT failures, associated with the description of relative energies of different spin states and their functional dependence, have been widely illustrated in the literature. ${ }^{32}$ Successively, as far as the low spin/high spin crossing is the rate determining step of this reaction, we study the influence of different experimental conditions on the spin-crossover barrier and, finally, we propose a simplified model for the whole process mechanism and we compare the calculated activation Gibbs free energy to high resolution kinetics data provided by Newcomb and co-workers. ${ }^{20}$ Error! Bookmark not defined. The results of this work will deliver the resolution of the apparent conundrum.

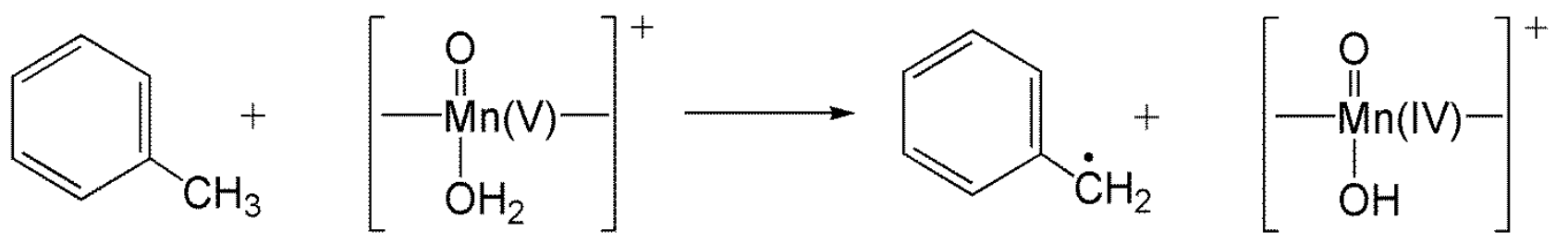


Scheme 1: Schematic representation of $\mathrm{H}$-abstraction process $\mathrm{MnOP}\left(\mathrm{H}_{2} \mathrm{O}\right)^{+}+\mathrm{C}_{6} \mathrm{H}_{5} \mathrm{CH}_{3}$ studied in this work.

\section{Computational details}

\section{DFT calculations}

DFT calculations were performed in the gas phase with the ADF 2014.04 program package, ${ }^{33}$ employing a BP86 functional, ${ }^{34}$ Grimme3 BJ damping dispersion corrections (DFT-D3-BJ), ${ }^{35}$ a Slater-type TZ2P quality basis set and a scalar ZORA Hamiltonian to include relativistic effects. ${ }^{36}$ The computation of the minimum energy crossing points (MECP) was carried out using a program developed by J.N. Harvey ${ }^{37}$ and interfaced with the ADF package, with the computational details described above. Activation free energy barriers $\Delta \mathrm{G}^{\ddagger}$ were calculated by means of analytical frequencies. The gas-phase $\Delta \mathrm{G}^{\ddagger}$ was computed as the sum of $\Delta \mathrm{H}^{*}$ and $-\mathrm{T} \Delta \mathrm{S}^{*}$ at $298.15 \mathrm{~K}$.

\section{DMRG-CASPT2/CC calculations}

A recently proposed approach, referred to as DMRG-CASPT2/CC, ${ }^{31}$ was employed in order to examine the reliability of the BP86 functional for the energetic description of the $\mathrm{MnOP}\left(\mathrm{H}_{2} \mathrm{O}\right)^{+}$ singlet/triplet energy gap. In this approach, DMRG-CASPT2 was used to describe valence electron correlation, whereas semicore (Mn 3s3p) electron correlation was described with low-cost coupled cluster $\operatorname{CCSD}(\mathrm{T})$. The active space consists of 16 orbitals for the singlet state, ${ }^{1} \mathrm{MnOP}\left(\mathrm{H}_{2} \mathrm{O}\right)^{+}$, and 17 orbitals for the triplet state, ${ }^{3} \mathrm{MnOP}\left(\mathrm{H}_{2} \mathrm{O}\right)^{+}$. This active space was built in order to account for the static correlation of the $\mathrm{Mn} 3 \mathrm{~d}$ shell, the covalency of the $\mathrm{Mn}=\mathrm{O}$ bond and the $\sigma$ donation from the porphyrin, by including four pairs of the following bonding/antibonding molecular orbitals: $\mathrm{Mn}$ $\left(3 \mathrm{~d}_{\mathrm{z} 2}\right)-\mathrm{O}\left(2 \mathrm{p}_{\mathrm{z}}\right)\left(\sigma_{\mathrm{z}}, \sigma_{\mathrm{z}}^{*}\right), \mathrm{Mn}\left(3 \mathrm{~d}_{\mathrm{xz}}\right)-\mathrm{O}\left(2 \mathrm{p}_{\mathrm{x}}\right)\left(\pi_{\mathrm{xz}}, \pi^{*} \mathrm{xz}\right), \mathrm{Mn}\left(3 \mathrm{~d}_{\mathrm{yz}}\right)-\mathrm{O}\left(2 \mathrm{p}_{\mathrm{y}}\right)\left(\pi_{\mathrm{yz}}, \pi^{*} \mathrm{yz}\right)$ and $\mathrm{Mn}\left(3 \mathrm{~d}_{\mathrm{xy}}\right)-\mathrm{P}\left(\sigma_{\mathrm{xy}}\right)$ $\left(\sigma_{\mathrm{xy}}, \sigma_{\mathrm{xy}}\right)$. We also included the non-bonding $\operatorname{Mn}\left(3 \mathrm{~d}_{\mathrm{xy}}\right)$ orbital and four additional $\pi$ orbitals on the porphyrin known as the Gouterman set containing two high-lying occupied $\pi$ orbitals, $\mathrm{P}\left(\pi \mathrm{a}_{1 \mathrm{u}}\right)$ and $\mathrm{P}$ $\left(\pi \mathrm{a}_{2 \mathrm{u}}\right.$ ), and the correlating P ( $\left.\pi^{*}{ }_{\mathrm{eg}}\right)$ orbitals. Finally, we modelled the so-called 'double-shell' effect of $\mathrm{Mn}$ and $\mathrm{O}$ by adding two oxygen orbitals ( $3 \mathrm{p}_{\mathrm{x}}$ and $3 \mathrm{p}_{\mathrm{y}}$ ) and one/two $\mathrm{Mn}(4 \mathrm{~d})$ orbitals for ${ }^{1} \mathrm{MnOP}\left(\mathrm{H}_{2} \mathrm{O}\right)^{+} / 3 \mathrm{MnOP}\left(\mathrm{H}_{2} \mathrm{O}\right)^{+}$, respectively. 
DMRG-CASPT2 calculations were carried out using the CheMPS2 code ${ }^{38}$ interfaced with the program OpenMolcas. ${ }^{39}$ The number of renormalized states $(m)$ is 2000 . An ANO-RCC type basis set was used with the following contractions: [7s6p5d3f2g1h] for the metal atom; ${ }^{40}[4 \mathrm{~s} 3 \mathrm{p} 2 \mathrm{~d} 1 \mathrm{f}]$ for O, $\mathrm{C}$ and $\mathrm{N} ;{ }^{41}$ and $\left[3 \mathrm{~s} 1 \mathrm{p}\right.$ ] for $\mathrm{H}^{42}$ To lower the computational cost, we employed the Cholesky decomposition technique for the two electron integrals ${ }^{43}$ with a threshold of $10^{-6}$ au. Scalar relativistic effects were taken into account with a standard second-order Douglas-Kroll-Hess (DKH) Hamiltonian. ${ }^{44}$

In all PT2 calculations, we used the standard ionization potential electron affinity (IPEA) shift of 0.25 au. ${ }^{45}$ An imaginary shift of 0.1 au was applied in order to prevent weak intruder states and improve convergence. ${ }^{46}$ Manganese (3s3p) correlation was described with the partially spin-restricted coupled cluster RCCSD(T) method as implemented in Molpro v.2012. ${ }^{47}$ The basis set was aug-cc-pwCVTZDK for $\mathrm{Mn}^{48}$ and MINAO for the remaining atoms. ${ }^{49}$

\section{Results and Discussion}

\section{Reactivity of $\mathrm{MnOP}\left(\mathrm{H}_{2} \mathrm{O}\right)^{+}$with toluene: $\mathrm{H}$-abstraction process}

To explore the $\mathrm{H}$-abstraction reactivity, we calculated a reaction profile using the MECP approach. It is depicted in Figure 1. The singlet reactant complex ${ }^{1} \mathrm{RC}$ is stabilized by $-6.5 \mathrm{kcal} / \mathrm{mol}$ with respect to the separated reactants. The MECP is placed at the beginning of the reaction and it represents the rate-determining-step (RDS) for this process with a low activation barrier $\left(\Delta \mathrm{E}^{\ddagger}\right.$ spin-cross $)$ of 3.7 $\mathrm{kcal} / \mathrm{mol}$. Thus the MECP is thermally accessible by the system since only $3.7 \mathrm{kcal} / \mathrm{mol}$ are needed to access the triplet PES within the accuracy of the BP86 functional. Then the triplet reactant complex ${ }^{3} \mathrm{RC}$ is formed and the substrate $\mathrm{H}$ atom is abstracted via a transition state located on the triplet PES $\left({ }^{3} \mathrm{TS}\right)$ at only $0.5 \mathrm{kcal} / \mathrm{mol}\left(\Delta \mathrm{E}^{\ddagger}\right.$ abstraction) above the triplet reactant complex ${ }^{3} \mathrm{RC}$. 


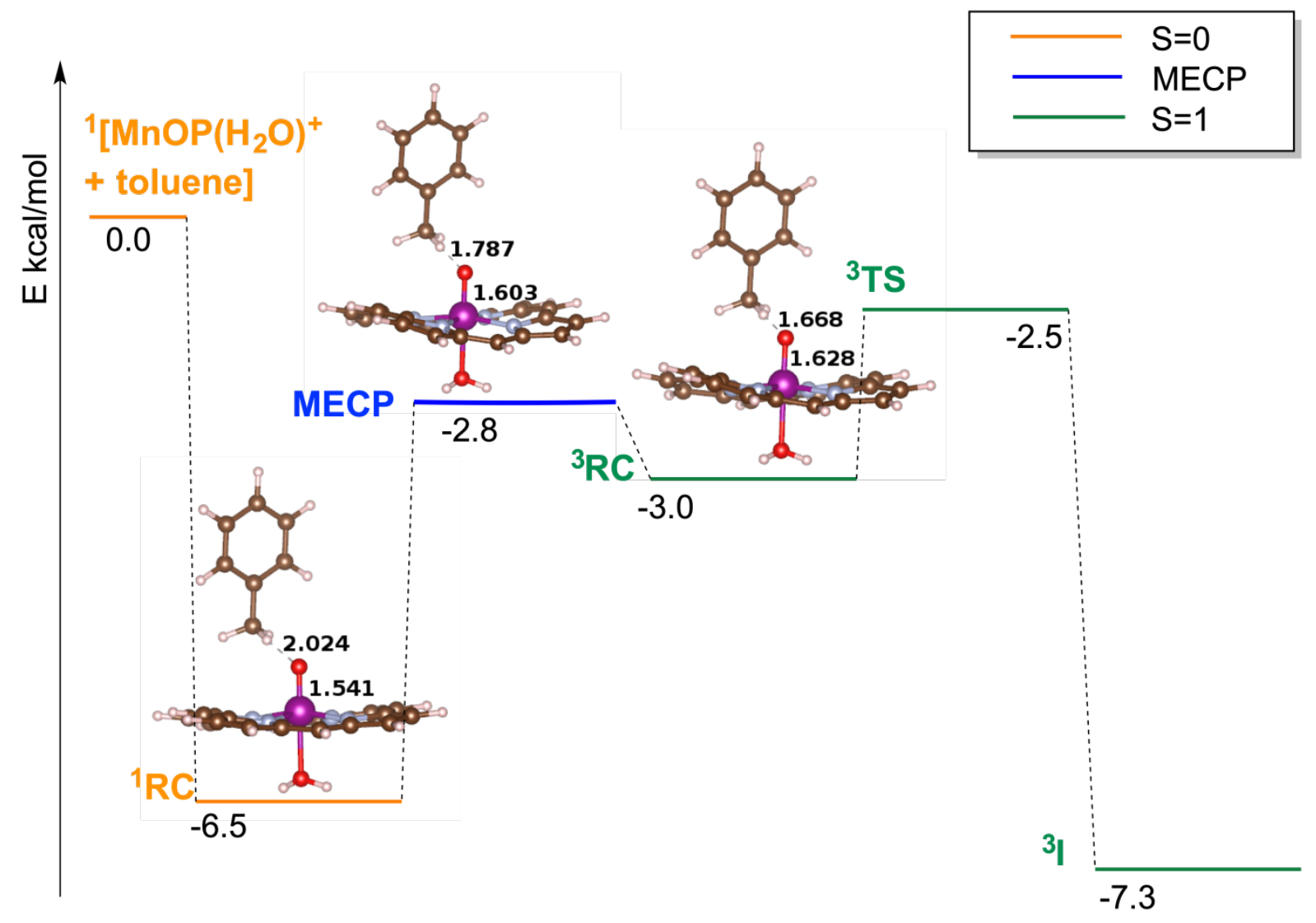

Figure 1: Reaction profile for the $\mathrm{H}$-abstraction from toluene by $\mathrm{MnOP}\left(\mathrm{H}_{2} \mathrm{O}\right)^{+}$.

On comparing the $\mathrm{O}-\mathrm{H}$ distance between the hydrogen of the methyl group of toluene and the oxo group of the catalyst we observe a large distance $(2.024 \AA)$ in the singlet reactant complex ${ }^{1} \mathrm{RC}$ and a reduced distance $(1.787 \AA)$ in the MECP structure which is close to that $(1.668 \AA)$ in the triplet reactant complex ${ }^{3} \mathrm{RC}$. These findings suggest that the process should occur through a preliminary spin-crossover taking place on the $\mathrm{MnOP}\left(\mathrm{H}_{2} \mathrm{O}\right)^{+}$complex from singlet to triplet and a subsequent $\mathrm{H}$ abstraction of the toluene hydrogen with a very low activation barrier of $0.5 \mathrm{kcal} / \mathrm{mol}$, promoted by the oxyl character of the triplet Mn-oxo-porphyrin complex.

Due to the importance of the spin-crossover on the Mn-oxo-porphyrin complex, it is interesting to compare the $\mathrm{MnOP}\left(\mathrm{H}_{2} \mathrm{O}\right)^{+}$optimized geometry for the singlet and triplet spin states. The structures are reported in Figure 2. 
Figure 2: $\mathrm{MnOP}\left(\mathrm{H}_{2} \mathrm{O}\right)^{+}$structure optimized in the singlet (left panel) and triplet (right panel) spin states. Distances are in $\AA$.

Concerning the $\mathrm{O}-\mathrm{Mn}-\mathrm{OH}_{2}$ moiety, we observe an increase of the Mn-oxo distance, from 1.531 to
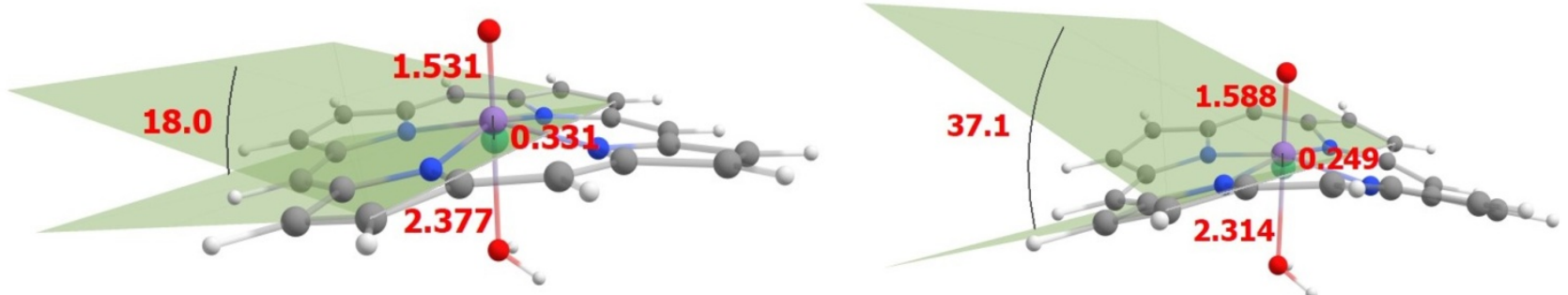

$1.588 \AA$, and a consequent shortening of the $\mathrm{Mn}-\mathrm{OH}_{2}$ one, from 2.377 to $2.314 \AA$, from singlet to triplet state. The Mn distance from the plane of the nitrogen atoms, defined as the distance between $\mathrm{Mn}$ and the centre of mass of the four $\mathrm{N}$ atoms shortens from 0.331 in the singlet to $0.249 \AA$ in the triplet.

The porphyrin equatorial ligand is also dramatically affected by the spin state change, with the major change being an enhancement of the ruffling distortion. Both the $\mathrm{MnOP}\left(\mathrm{H}_{2} \mathrm{O}\right)^{+}$singlet and triplet structures are found in a ruffling conformation which can be measured by a ruffling dihedral angle relating to the positions of four carbons atom located at the bottom of two opposite pyrroles (see Figure S1 in the SI). The ruffling can be envisaged as twisting along the Mn-N(pyrrole) bonds in alternate directions, resulting in an out-of-plane distortion for the porphyrin. The ruffling dihedral angle increases from $18.0^{\circ}$ in the singlet to $37.1^{\circ}$ in the triplet, thus indicating that the spin state change in the complex significantly affects the conformation of the porphyrin ligand. The ruffling distortion of the system under study is analogous to the one experienced by the biochemically relevant heme group. ${ }^{50}$ It has been recently demonstrated, by employing the simplified model of bisimidazole-coordinate Fe porphyrins, that the ruffling distortion reduces the redox potential of heme, making it a more effective oxidant. ${ }^{49}$

The singlet-triplet energy difference for the $\mathrm{MnOP}\left(\mathrm{H}_{2} \mathrm{O}\right)^{+}$complex is calculated to amount to 6.5 $\mathrm{kcal} / \mathrm{mol}$, with the singlet as the ground spin state. These findings are in complete agreement with previous results from ref. 30, where three different spin states, the singlet, triplet and quintet, were computed for $\left[\mathrm{MnO}(\mathrm{tHp})\left(\mathrm{H}_{2} \mathrm{O}\right)\right]^{+}(\mathrm{tHp}=$ tetrahydrogenporphyrin), with the singlet being the ground state and the triplet and quintet states lying 4.7 and $12.1 \mathrm{kcal} / \mathrm{mol}$, respectively, above the singlet. The structural variation trend is also reproduced, with the $\mathrm{Mn}=\mathrm{O}$ distance elongating from singlet (1.55 $\AA$ ) to triplet $(1.61 \AA)$ and quintet $(1.68 \AA)$ and the $\mathrm{Mn}-\mathrm{OH}_{2}$ bond shortening from singlet $(2.22 \AA)$ to triplet $\left(2.17 \AA\right.$ ) and quintet $(2.16 \AA) .{ }^{30}$ 


\section{Validation of the computational approach: DFT vs DMRG-CASPT2/CC}

In order to have an idea on the reliability of the BP86 functional for the evaluation of the spincrossover energy barrier we performed single point DMRG-CASPT2/CC calculations on the two spin states, singlet and triplet, of the $\mathrm{MnOP}\left(\mathrm{H}_{2} \mathrm{O}\right)^{+}$complex and we compared their gap value with the one provided by BP86. It has been shown that DMRG-CASPT2/CC is capable of providing accurate spin state energetics of the first-row transition metal compounds with an error of a few $\mathrm{kcal} / \mathrm{mol} .^{31}$

The $\mathrm{MnO}\left(\mathrm{H}_{2} \mathrm{O}\right)^{+}$porphyrin geometries employed for these single point calculations were optimized with our previously described computational set up in a $\mathrm{C}_{\mathrm{s}}$ symmetry. The singlet-triplet energy difference predicted by the BP86 functional is now $6.8 \mathrm{kcal} / \mathrm{mol}(6.5 \mathrm{kcal} / \mathrm{mol}$ without symmetry constraint). DMRG-CASPT2 with only valence electrons correlated gives a singlet-triplet energy difference of $3.3 \mathrm{kcal} / \mathrm{mol}$. In agreement with previous works, ${ }^{31}(3 \mathrm{~s} 3 \mathrm{p})$ electron correlation calculated with $\operatorname{CCSD}(\mathrm{T})$ favors the low-spin over high-spin state (by $1.7 \mathrm{kcal} / \mathrm{mol}$ ). The final energy gap between singlet and triplet predicted by DMRG-CASPT2/CC is estimated to be $4.9 \mathrm{kcal} / \mathrm{mol}$. We could state that the energy description of the spin states provided by the BP86 functional is $(6.8$ $\mathrm{kcal} / \mathrm{mol}$ ) in good agreement with the DMRG-CASPT2/CC one and, thus, it is accurate for the modeling of the system.

Interestingly, the orbitals occupation numbers of the CASSCF calculation provide evidence that the main contribution to the triplet wavefunction arises from a configuration in which an electron is excited from a Mn $3 \mathrm{~d}_{\mathrm{xy}}$ orbital to a Mn-oxo $\pi^{*}$ one (see Figure S2 in the SI). This explains the elongation of the Mn-oxo distance in the triplet state complex, since a non-bonding electron is promoted to an anti-bonding Mn-oxo orbital and clarifies the fact that, for the triplet, the main charge transfer contributions comes from the metal center and not from the porphyrin ligand.

All these results are in good agreement with those found by Pierloot and co-workers ${ }^{28}$ for a Mn(V)oxo-porphyrin system without any axial ligand. Here we find that the introduction of the water in trans position to $\mathrm{Mn}(\mathrm{V})$-oxo group does not change the electronic configuration of the spin state, it solely contributes to lower the singlet-triplet energy gap $(5.6 \mathrm{kcal} / \mathrm{mol}$ in ref. $28 \mathrm{vs} .4 .9 \mathrm{kcal} / \mathrm{mol}$ in this work).

\section{Axial ligand influence on reactivity}

Highlighting how the different solution conditions influence the reactivity of the Mn-oxo porphyrin complex is very important to improve its catalytic efficiency. The presence in solution of species like ions, solvent molecules or base able to coordinate to the Mn atom could have an impact on the catalyst reactivity. 
The role of the acidity on the reactivity of Mn-porphyrin has been experimentally reported by Groves and co-workers, ${ }^{23}$ and it was theoretically studied by Groves and co-workers ${ }^{29}$ and later on by Eisenstein and co-workers. ${ }^{30}$ Eisenstein and co-workers showed that different axial ligands, modeling the $\mathrm{pH}$-dependent $\mathrm{Mn}$-oxo porphyrin reactivity, namely $\mathrm{H}_{2} \mathrm{O}$ at low $\mathrm{pH}, \mathrm{OH}^{-}$at intermediate $\mathrm{pH}$ and $\mathrm{O}^{2-}$ at high $\mathrm{pH}$ values, change the reactivity of the catalyst. Based on literature results, ${ }^{30}$ we also propose here that the reactivity of the Mn-oxo porphyrin complex is tuned by the singlet/triplet energy gap, with smaller gaps corresponding to more reactive complexes. Thus we carried out several geometry optimizations by replacing the axial water with different $\mathrm{X}$ ligands (specifically $\mathrm{X}=\mathrm{OH}^{-}$, $\mathrm{O}^{2-}, \mathrm{CH}_{3} \mathrm{CN}, \mathrm{Cl}^{-}$and none) to investigate how the singlet-triplet energy gap is quantitatively influenced.

From a geometrical perspective, we have found that the influence provided by the axial ligands is driven by both their basicity and charge. The $\mathrm{Mn}=\mathrm{O}$ distance has been found to change in the order none $\approx \mathrm{CH}_{3} \mathrm{CN} \approx \mathrm{H}_{2} \mathrm{O}<\mathrm{Cl}^{-} \approx \mathrm{OH}^{-}<\mathrm{O}^{2-}$ in both the singlet and triplet spin states (see Figure $\mathrm{S} 3$ in the SI).

As we could expect, the $\mathrm{Mn}=\mathrm{O}$ distance increases with the basicity of the axial ligand, whereas it appears to be much less affected by the charge of the ligand. Interestingly, in the case of $\mathrm{OH}^{-}$and $\mathrm{Cl}^{-}$, the $\mathrm{Mn}=\mathrm{O}$ bond is not orthogonal to the porphyrin plane (the angle in these cases changes from 90 to about 85 degrees) (see Figure S4 in the SI). The same trend, although in the reverse order (decreasing with basicity), has been observed for the ruffling dihedral angle of the porphyrin in both the singlet and triplet spin states: $\mathrm{O}^{2-}<\mathrm{OH}^{-} \approx \mathrm{Cl}^{-}<\mathrm{CH}_{3} \mathrm{CN} \approx \mathrm{H}_{2} \mathrm{O} \approx$ none (see Figure S5 in the SI).

Interestingly, in the case of the $\mathrm{O}^{2-}$ ligand the porphyrin is flat in both the two different spin states, whereas for $\mathrm{OH}^{-}$and $\mathrm{Cl}^{-}$it is flat in the singlet state and it is ruffled by $21.1-22.0^{\circ}$ in the triplet state. For $\mathrm{H}_{2} \mathrm{O}, \mathrm{CH}_{3} \mathrm{CN}$ and the bare complex (none) the porphyrin is ruffled by $36.4-37.1^{\circ}$ in the triplet state, and it shows different values of the ruffling dihedral angle in the singlet state (18.0, 7.4 and $27.0^{\circ}$, respectively) (see Figure S5 in the SI). Generally, in the triplet spin state the porphyrin ruffling is significantly larger than in the singlet state for all the considered ligands, thus suggesting that the ruffling distortion might be associated with an enhanced reactivity, analogously to what it has been found for the heme group. ${ }^{50}$ 
Finally, the Mn-X distance follows the trend $\mathrm{O}^{2-}<\mathrm{OH}^{-}<\mathrm{Cl}^{-}<\mathrm{CH}_{3} \mathrm{CN} \approx \mathrm{H}_{2} \mathrm{O}$ in the singlet state and $\mathrm{O}^{2-}<\mathrm{OH}^{-}<\mathrm{CH}_{3} \mathrm{CN}<\mathrm{H}_{2} \mathrm{O} \approx \mathrm{Cl}^{-}$in the triplet spin state, as shown in Figure $\mathrm{S} 6$ in the SI. Generally we observe that the $\mathrm{Mn}-\mathrm{X}$ distances are larger for the triplet than for the singlet state, apart from water and acetonitrile where this trend is reversed (Figure S6), and that they are mostly tuned by the basicity of the axial ligand rather than by its charge.

Table S1 in the SI summarizes for each species the most important geometrical parameters and the energy gap between singlet and triplet states.

We find that the singlet-triplet gap increases along the series $\mathrm{Cl}^{-}(5.7 \mathrm{kcal} / \mathrm{mol})<\mathrm{H}_{2} \mathrm{O}(6.5 \mathrm{kcal} / \mathrm{mol})$ $<$ none $(9.8 \mathrm{kcal} / \mathrm{mol}) \approx \mathrm{OH}^{-}(9.8 \mathrm{kcal} / \mathrm{mol})<\mathrm{CH}_{3} \mathrm{CN}(10.2 \mathrm{kcal} / \mathrm{mol})<<\mathrm{O}^{2-}(28.4 \mathrm{kcal} / \mathrm{mol})$, with $\mathrm{O}^{2-}$ yielding a much larger gap than all the other ligands. Notably no correlation can be found between structural data and the $[\mathrm{MnOP}(\mathrm{X})]^{+}$singlet-triplet energy gap.

On the other hand, the reactivity has been previously reported to be entirely controlled by the large increase in the singlet-triplet gap caused by high trans influence ligands by Eisenstein and coworkers $^{30}$ and Groves and co-workers ${ }^{29}$ for Mn-catalyzed C-H and bromide oxidation, respectively, where $\mathrm{X}=\mathrm{H}_{2} \mathrm{O}, \mathrm{OH}^{-}$and $\mathrm{O}^{2-}$. Thus, the reactivity trend we calculate here in the $\mathrm{C}-\mathrm{H}$ oxidation of toluene could be rationalized in terms of the electronic structure of the $[\mathrm{MnOP}(\mathrm{X})]^{+}$intermediates. Frontier molecular orbital diagrams of all the $[\operatorname{MnOP}(\mathrm{X})]^{+}$complexes are provided in Figure 3.
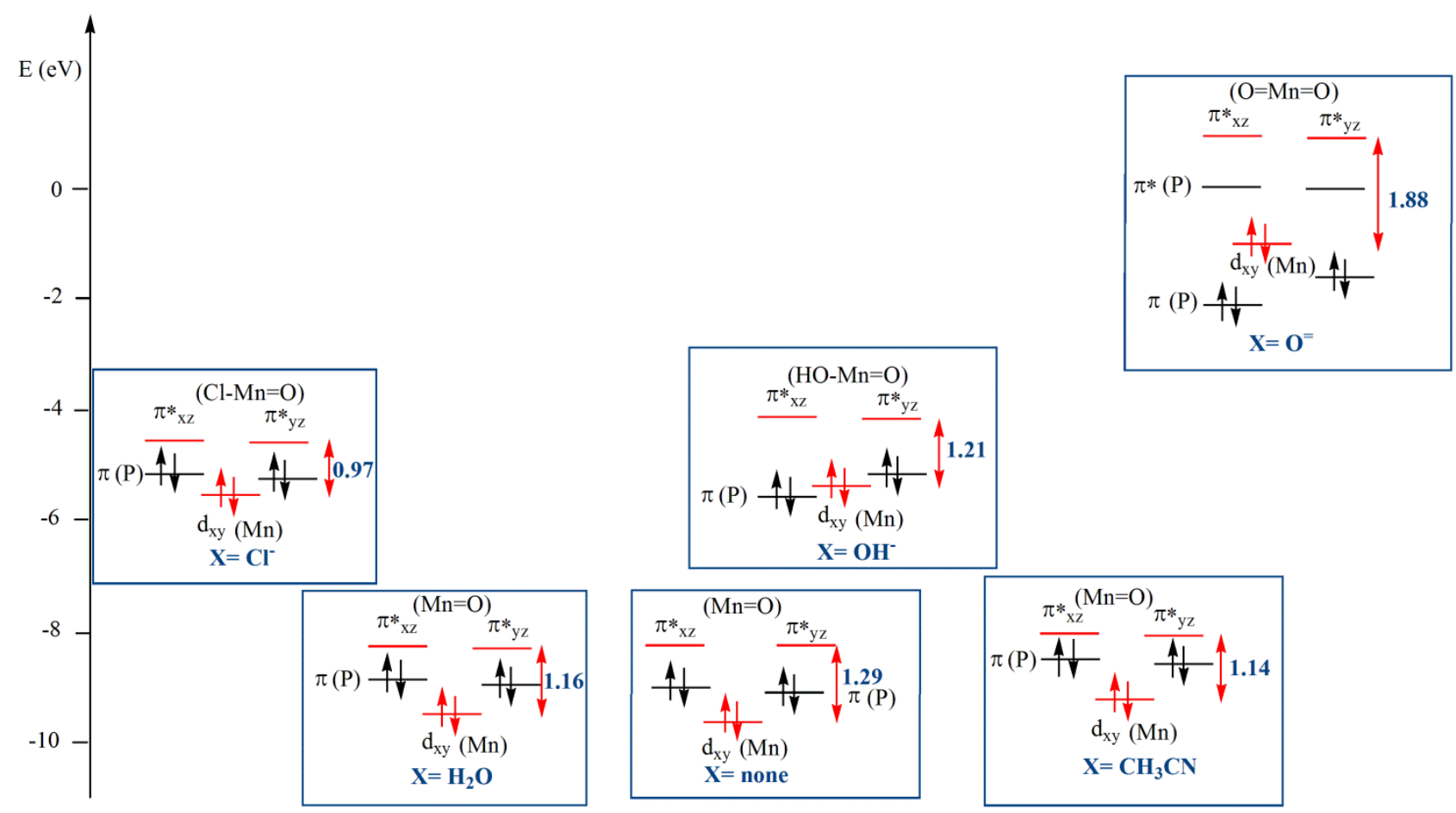
Figure 3: Frontier molecular orbitals for the singlet state of $[\mathrm{MnOP}(\mathrm{X})]^{+}\left(\mathrm{X}=\right.$ none, $\mathrm{CH}_{3} \mathrm{CN} \mathrm{Cl}^{-}$, $\left.\mathrm{H}_{2} \mathrm{O}, \mathrm{OH}^{-}, \mathrm{O}^{2-}\right)$ complex series. Orbitals involved in the electron promotion leading to the triplet state are in red color. Energy difference between these orbitals is also reported (in eV). Labels for $\pi^{*}$ orbitals indicate the presence $(\mathrm{X}-\mathrm{Mn}=\mathrm{O})$ or the absence $(\mathrm{Mn}=\mathrm{O})$ of contribution from the axial ligand.

In the singlet ground state the two $3 \mathrm{~d}$ electrons of the $\mathrm{Mn}(\mathrm{V})$ center are paired in one nonbonding $3 \mathrm{~d}_{\delta}$-like MO $\left(3 \mathrm{~d}_{\mathrm{xy}}\right)$. The Mn-O $\sigma$ bond arises from bonding/antibonding combinations of $\mathrm{Mn} \mathrm{d}_{\mathrm{z} 2}$ and $\mathrm{O} \mathrm{p}_{\mathrm{z}}\left(\sigma, \sigma^{*}\right)$ and a double $\pi$ bond is formed from bonding/antibonding MO pairs between Mn $\left(\mathrm{d}_{\mathrm{xz}}\right.$, $\left.\mathrm{d}_{\mathrm{yz}}\right)$ and $\mathrm{O}\left(\mathrm{p}_{\mathrm{x}}, \mathrm{p}_{\mathrm{y}}\right)\left(\pi_{\mathrm{xz}}, \pi_{\mathrm{yz}}, \pi_{\mathrm{xz}}{ }^{*}, \pi_{\mathrm{yz}}{ }^{*}\right)$, with different axial ligand participation $(\mathrm{X}-\mathrm{Mn}=\mathrm{O})$. The three bonding combinations $\sigma, \pi_{\mathrm{xz}}$, and $\pi_{\mathrm{yz}}$ (not shown in Figure 3 ) are fully occupied, whereas the corresponding antibonding MOs $\sigma^{*}, \pi_{\mathrm{xz}}{ }^{*}$, and $\pi_{\mathrm{yz}}{ }^{*}$ remain empty, giving rise to a triple Mn-O bond lacking oxygen radical character. For all the complexes, except $[\mathrm{MnOP}(\mathrm{O})]^{-}$, the HOMOs are the two $\pi$ orbitals of the porphyrin ligand which are close in energy and are located above the doubly occupied $M n d_{x y}$, which represents instead the HOMO in the case $\mathrm{X}=\mathrm{O}^{2-}$. The LUMOs are the two almost degenerate $\pi^{*}(\mathrm{Mn}=\mathrm{O})$ orbitals $\left(\pi_{\mathrm{xz}} *\right.$ and $\left.\pi_{\mathrm{yz}}{ }^{*}\right)$, which can raise their energies by antibonding mixing with the axial ligand. For $\mathrm{X}=\mathrm{O}^{2-}$ having a high trans influence, the energy of the $\pi^{*}(\mathrm{O}=\mathrm{Mn}=\mathrm{O})$ orbitals is increased, and they locate above the two $\pi^{*}$ orbitals of the porphyrin which become the LUMOs. Interestingly, the axial $\mathrm{H}_{2} \mathrm{O}$ and $\mathrm{CH}_{3} \mathrm{CN}$ ligands do not mix with the $\pi^{*}(\mathrm{Mn}=\mathrm{O})$. In the case of $\mathrm{H}_{2} \mathrm{O}$, the lone pair is far removed in energy from the $\pi^{*}(\mathrm{Mn}=\mathrm{O})$ orbital and therefore does not overlap with the metal d orbitals. For $\mathrm{OH}^{-}$, instead, the lone pairs are more diffuse and close in energy to $\pi^{*}(\mathrm{Mn}=\mathrm{O})$, thus favoring the overlap with the $\mathrm{Mn} \mathrm{d}$ orbitals. As a consequence, the axial $\mathrm{OH}^{-}$ ligand participates in the $\pi$ interactions of the $\mathrm{HO}-\mathrm{Mn}=\mathrm{O}$ moiety which raises in energy the $\pi *$ orbitals $(\mathrm{HO}-\mathrm{Mn}=\mathrm{O})$. Analogously, the fully occupied $\mathrm{p}_{\mathrm{x}}$ and $\mathrm{p}_{\mathrm{y}}$ nonbonding combinations of the axial $\mathrm{Cl}^{-}$ ligand overlap with $\mathrm{Mn}$ d orbitals, thus participating in the $\pi^{*}$ orbitals $(\mathrm{Cl}-\mathrm{Mn}=\mathrm{O})$ and pushing them up in energy (although to a lesser extent than the axial $\mathrm{OH}^{-}$). In the case of $\mathrm{O}^{2-}$, the overlap between the metal $d$ orbitals and the fully occupied $p_{x}$ and $p_{y}$ orbitals of the trans oxygens is large. Consequently, the strong involvement of both oxygens in the $\pi^{*}$ orbitals $(\mathrm{O}=\mathrm{Mn}=\mathrm{O})$ increases their energy substantially. The triplet state for all of the complexes invariably arises from the promotion of one electron from the doubly occupied $\mathrm{Mn} 3 \mathrm{~d}_{\mathrm{xy}}$ orbital to one of the antibonding $\pi^{*}(\mathrm{X}-\mathrm{M}=\mathrm{O})$ orbitals, which becomes singly occupied. These orbitals are depicted in Figure S7 in the SI for all the complexes. This explains the weakening of the $\mathrm{Mn}=\mathrm{O}$ bond and the gain in oxyl character in the triplet state. According to ref. 30, the singlet-triplet energy gap is mainly determined by the energy of these orbitals. In Figure 3 the $\mathrm{Mn} 3 \mathrm{~d}_{\mathrm{xy}}-\pi^{*}(\mathrm{X}-\mathrm{M}=\mathrm{O})$ energy gap is shown for all the different 
ligands. The trend reported by Eisenstein and co-workers ${ }^{30}$ for the axial ligand series $\mathrm{X}=\mathrm{H}_{2} \mathrm{O}, \mathrm{OH}^{-}$ and $\mathrm{O}^{2-}$ is well reproduced, and a good correlation between the singlet/triplet energy gaps and the $\mathrm{Mn}$ $3 \mathrm{~d}_{\mathrm{xy}}-\pi^{*}(\mathrm{X}-\mathrm{M}=\mathrm{O})$ energy differences is found within the entire series of axial ligands, as shown in Figure 4.

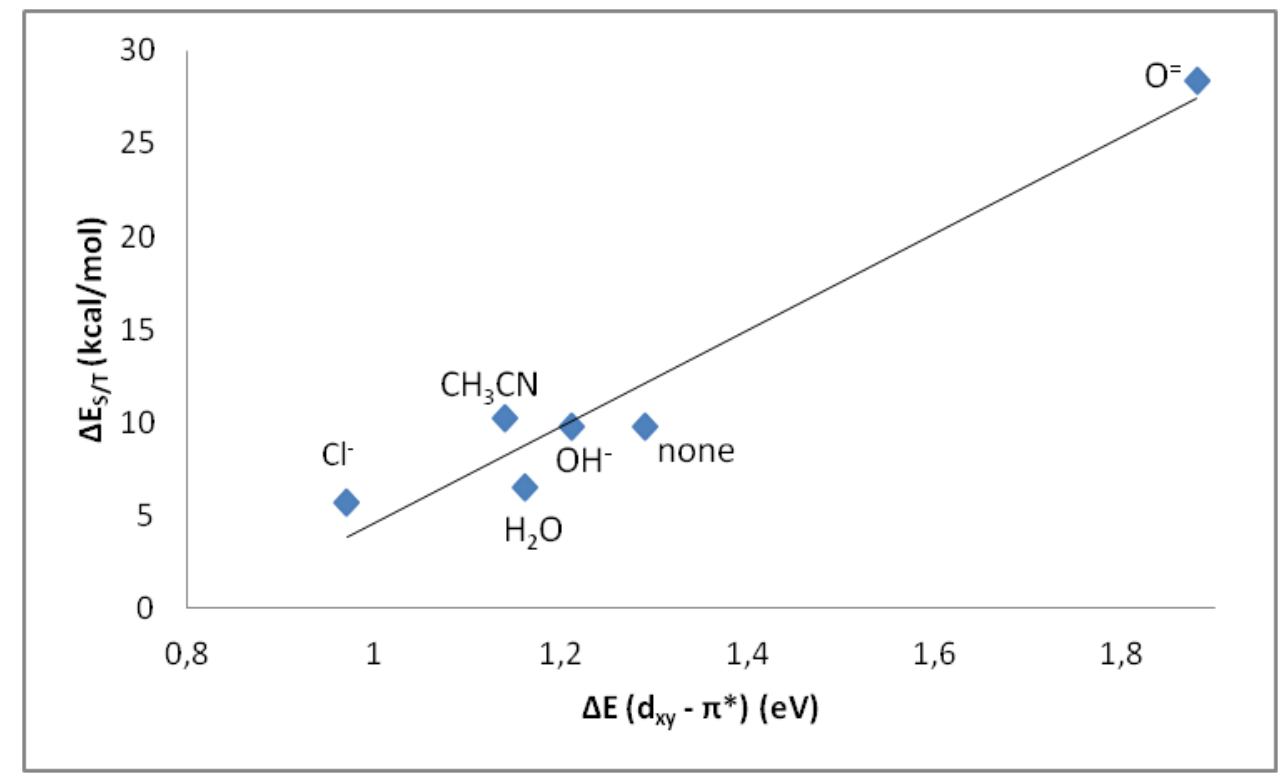

Figure 4: Correlation plot between singlet/triplet energy gap $\left(\Delta \mathrm{E}_{\mathrm{S} / \mathrm{T}}\right)(\mathrm{kcal} / \mathrm{mol})$ and $\mathrm{Mn} 3 \mathrm{~d}_{\mathrm{xy}}-\pi^{*}(\mathrm{X}-$ $\mathrm{M}=\mathrm{O})$ energy difference $\left(\Delta \mathrm{E}\left(\mathrm{d}_{\mathrm{xy}}-\pi^{*}\right)\right)(\mathrm{eV})$ for all the $[\mathrm{MnOP}(\mathrm{X})]^{+}\left(\mathrm{X}=\right.$ none, $\mathrm{CH}_{3} \mathrm{CN}, \mathrm{Cl}^{-}, \mathrm{H}_{2} \mathrm{O}$, $\left.\mathrm{OH}^{-}, \mathrm{O}^{2-}\right)$ complex series $\left(\mathrm{R}^{2}=0.9463\right)$.

These results confirm the finding that the reactivity (and then the singlet/triplet energy gap) is mainly controlled by the axial ligand trans influence. ${ }^{30}$

The $\pi^{*}(\mathrm{X}-\mathrm{M}=\mathrm{O})$ orbitals are key for reactivity since they act as electron acceptors for the $\mathrm{C}-\mathrm{H}$ bond breaking (" $\pi$-channel reactivity"). Generally speaking, the lower the acceptor orbital lies in energy and the higher the oxo oxygen contribution is, the more electrophilic the $\mathrm{Mn}(\mathrm{V}) \mathrm{O}$ moiety will be. From a ligand-field perspective, on the basis of our results, we can observe that i) the spin state (both singlet and triplet) in the $[\mathrm{MnOP}(\mathrm{X})]^{+}$complex series is determined by the nature of the equatorial ligands (P) alone, irrespective of the nature of the axial ligand; ii) the triplet state is the reactive state in contrast to the singlet in hydrogen abstraction; iii) the reactivity of the triplet is driven by transfer of an electron to a low-lying $\pi^{*}$ orbital; and iv) the axial ligand (X) regulates the reactivity of the complex by inducing relatively minor shifts in the energy of the lowest-lying $\pi^{*}$ orbital through $\mathrm{X}$ $\mathrm{Mn}=\mathrm{O} \pi$ antibonding interactions. An indirect axial ligand effect arises from charge build up, that is ligands donating electron charge to the metal center, which will decrease the positive charge on the 
metal and the Mn-oxo group. Positive charge on that group is important for the lowering of the barrier to $\mathrm{H}$ abstraction, since it lowers the energy of the electron acceptor orbital. Charge exerts a strong effect, when charged ligands are considered: negative charge (for instance $\mathrm{O}^{2-}$ ) sizably increases the energy of the $\pi^{*}$ acceptor orbital, in agreement with the trend of decreasing reactivity with increasing electron donation $\left(\mathrm{H}_{2} \mathrm{O}>\mathrm{OH}^{-}>\mathrm{O}^{2-}\right)$. These ligand field effects have been further tested with additional calculations for different axial ligands $\left(\mathrm{X}=\mathrm{CN}^{-}, \mathrm{ClO}_{3}^{-}, \mathrm{NO}_{3}^{-}, \mathrm{NH}_{3}\right.$ and $\left.\mathrm{SCN}^{-}\right)$which confirm the previous findings. Results concerning geometries and energies are reported in Tables S2 and S3 the SI. Analogously, the triplet state for all of the additional complexes arises from the promotion of one electron from the doubly occupied Mn $3 \mathrm{~d}_{\mathrm{xy}}$ orbital to one of the antibonding $\pi^{*}(\mathrm{X}$ $\mathrm{M}=\mathrm{O}$ ) orbitals, which is responsible for the weakening of the $\mathrm{Mn}=\mathrm{O}$ bond and the gain in oxyl character in the triplet state. The singlet-triplet gap trend along the whole ligand series is now modified as follows: $\mathrm{SCN}^{-}(\mathrm{S}-$ bonded $)(3.8 \mathrm{kcal} / \mathrm{mol})<\mathrm{NO}_{3}{ }^{-}(4.8 \mathrm{kcal} / \mathrm{mol})<\mathrm{CN}^{-}(4.9 \mathrm{kcal} / \mathrm{mol})<$ $\mathrm{Cl}^{-}(5.7 \mathrm{kcal} / \mathrm{mol})<\mathrm{ClO}_{3}{ }^{-}(5.8 \mathrm{kcal} / \mathrm{mol})<\mathrm{H}_{2} \mathrm{O}(6.5 \mathrm{kcal} / \mathrm{mol})<$ none $(9.8 \mathrm{kcal} / \mathrm{mol}) \approx \mathrm{OH}^{-}(9.8$ $\mathrm{kcal} / \mathrm{mol})<\mathrm{CH}_{3} \mathrm{CN}(10.2 \mathrm{kcal} / \mathrm{mol})<\mathrm{NH}_{3}(10.7 \mathrm{kcal} / \mathrm{mol})<<\mathrm{O}^{2-}(28.4 \mathrm{kcal} / \mathrm{mol})$, with the doubly negative $\mathrm{O}^{2-}$ yielding again a much larger gap than all the other ligands.

However, when comparing ligands with similarly small trans influence in complexes with the same +1 charge, namely $\mathrm{X}=\mathrm{H}_{2} \mathrm{O}, \mathrm{CH}_{3} \mathrm{CN}$, and none, the correlation between the singlet/triplet energy gaps and the $\mathrm{Mn} 3 \mathrm{~d}_{\mathrm{xy}}-\pi^{*}(\mathrm{X}-\mathrm{M}=\mathrm{O})$ energy differences is lost. Indeed, within this ligand subset the largest singlet/triplet energy gap is calculated for $\mathrm{CH}_{3} \mathrm{CN}$ which shows a $\mathrm{Mn} 3 \mathrm{~d}_{\mathrm{xy}}-\pi^{*}(\mathrm{M}=\mathrm{O})$ energy difference very close to that calculated for $\mathrm{H}_{2} \mathrm{O}$ (1.14 vs. $1.16 \mathrm{eV}$, respectively) and smaller than that of $\mathrm{X}=$ none $(1.29 \mathrm{eV})$. This finding suggests that other factors than trans influence might tune the reactivity. One factor could be the porphyrin ruffling distortion, which is surprisingly small in $\left[\mathrm{MnOP}\left(\mathrm{CH}_{3} \mathrm{CN}\right)\right]^{+}\left(\mathrm{RDA}=7.4^{\circ}\right)$, larger in the $\left[\mathrm{MnOP}\left(\mathrm{H}_{2} \mathrm{O}\right)\right]^{+}\left(\mathrm{RDA}=17.9^{\circ}\right)$, and the largest in the $[\mathrm{MnOP}]^{+}\left(\mathrm{RDA}=27.0^{\circ}\right)$ singlet state. In Figure 5 the $\mathrm{Mn} 3 \mathrm{~d}_{\mathrm{xy}}$ and $\pi^{*}(\mathrm{M}=\mathrm{O})$ orbitals for $\mathrm{X}=$ none, $\mathrm{H}_{2} \mathrm{O}$ and $\mathrm{CH}_{3} \mathrm{CN}$ are shown in more detail. 

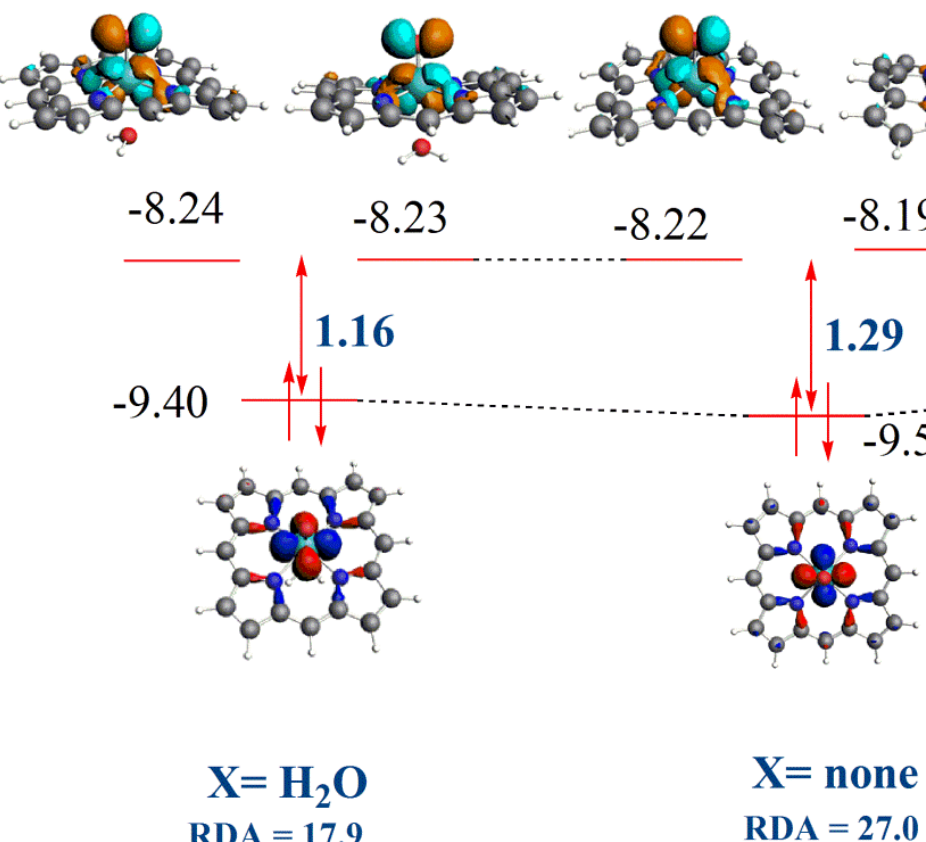

RDA $=17.9$

RDA $=\mathbf{2 7 . 0}$
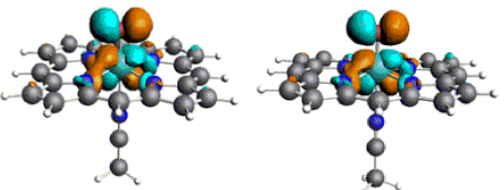

$-8.00$

$\mathrm{X}=\mathrm{CH}_{3} \mathrm{CN}$

RDA $=7.4$

Figure 5: $\mathrm{Mn} 3 \mathrm{~d}_{\mathrm{xy}}$ and $\pi^{*}(\mathrm{M}=\mathrm{O})$ molecular orbitals for the singlet state of $[\mathrm{MnOP}(\mathrm{X})]^{+}(\mathrm{X}=$ none, $\mathrm{CH}_{3} \mathrm{CN}, \mathrm{H}_{2} \mathrm{O}$ ) complex subset. Ruffling dihedral angles (RDA) (in degrees) and orbital energies values (in $\mathrm{eV}$ ) are also reported.

On comparing $\mathrm{X}=$ none and $\mathrm{X}=\mathrm{H}_{2} \mathrm{O}$, we see that the $\mathrm{Mn} 3 \mathrm{~d}_{\mathrm{xy}}-\pi^{*}(\mathrm{M}=\mathrm{O})$ energy difference (1.29 vs. $1.16 \mathrm{eV}$, respectively) is entirely due to $\mathrm{Mn} 3 \mathrm{~d}_{\mathrm{xy}}$ destabilization arising from antibonding mixing with porphyrin for $\mathrm{X}=\mathrm{H}_{2} \mathrm{O}$ (-9.51 vs. $-9.40 \mathrm{eV}$, respectively), accounting for $\Delta \mathrm{E}_{\mathrm{S} / \mathrm{T}}$ decreasing in $\left[\mathrm{MnOP}\left(\mathrm{H}_{2} \mathrm{O}\right)\right]^{+}(6.5$ vs. $9.8 \mathrm{kcal} / \mathrm{mol}$, respectively). Thus, the porphyrin ruffling effect should be that of stabilizing the singlet ground state, enhancing the singlet/triplet gap and making the system less reactive. This effect can be also seen for the almost flat $\mathrm{X}=\mathrm{CH}_{3} \mathrm{CN}$, where the $\mathrm{Mn} 3 \mathrm{~d}_{\mathrm{xy}}$ destabilization is even higher (-9.51 vs. $-9.14 \mathrm{eV}$, respectively). On this basis we could estimate a Mn $3 d_{\mathrm{xy}}-\pi^{*}$ $(\mathrm{M}=\mathrm{O})$ energy difference of about $0.92 \mathrm{eV}$ and a decreased $\Delta \mathrm{E}_{\mathrm{S} / \mathrm{T}}$ in $\left[\mathrm{MnOP}\left(\mathrm{CH}_{3} \mathrm{CN}\right)\right]^{+}$which is not observed $(10.2 \mathrm{kcal} / \mathrm{mol})$. Actually, we note that the porphyrin ruffling also affects the energy of $\pi^{*}$ $(\mathrm{M}=\mathrm{O})$ orbitals, which are analogously stabilized with respect to the "flat" conformation (compare the $\pi^{*}$ energy for $\mathrm{X}=$ none, $-8.22 \mathrm{eV}$ to that for $\left.\mathrm{X}=\mathrm{CH}_{3} \mathrm{CN},-8.00 \mathrm{eV}\right)$. The $\pi^{*}$ destabilization in "flat" $\left[\mathrm{MnOP}\left(\mathrm{CH}_{3} \mathrm{CN}\right)\right]^{+}$accounts for $0.22 \mathrm{eV}$ which sums up to the $0.92 \mathrm{eV}$ estimate of the $\mathrm{Mn} 3 \mathrm{~d}_{\mathrm{xy}}$ 
- $\pi^{*}(\mathrm{M}=\mathrm{O})$ energy difference, leading to the calculated $1.14 \mathrm{eV}$ value. From these considerations the singlet ground state of $\left[\mathrm{MnOP}\left(\mathrm{CH}_{3} \mathrm{CN}\right)\right]^{+}$should be the least stable and the smallest $\Delta \mathrm{E}_{\mathrm{S} / \mathrm{T}}$ should be expected in the ligand subset. However, in the triplet state a porphyrin ruffling of the same amount is observed in all the complexes: $[\mathrm{MnOP}]^{+}\left(\mathrm{RDA}=37.0^{\circ}\right),\left[\mathrm{MnOP}\left(\mathrm{H}_{2} \mathrm{O}\right)\right]^{+}\left(\mathrm{RDA}=37.1^{\circ}\right)$, and $\left[\mathrm{MnOP}\left(\mathrm{CH}_{3} \mathrm{CN}\right)\right]^{+}\left(\mathrm{RDA}=36.4^{\circ}\right)$, with $\mathrm{X}=\mathrm{CH}_{3} \mathrm{CN}$ experiencing the largest porphyrin conformation variation $\left(\triangle \mathrm{RDA}=29.0^{\circ}\right)$. Thus, we might surmise that for $\mathrm{X}=\mathrm{CH}_{3} \mathrm{CN}$ the largest $\Delta \mathrm{E}_{\mathrm{S} / \mathrm{T}}$ could be ascribed to an even less stable triplet, arising from the porphyrin ruffling. Then, within this ligand subset, the porphyrin conformational variation occurring from singlet to triplet does not allow to correlate the $\Delta \mathrm{E}_{\mathrm{S} / \mathrm{T}}$ with the $\mathrm{Mn} 3 \mathrm{~d}_{\mathrm{xy}}-\pi^{*}(\mathrm{M}=\mathrm{O})$ energy difference in the singlet. To further explore the idea that ruffling distortion could influence the reactivity, additional calculations have been performed by fixing the conformation of the porphyrin ligand to that observed for $\mathrm{X}=$ none $(\mathrm{RDA}=$ $27.0^{\circ}$ in the singlet and $37.0^{\circ}$ in the triplet) and varying the axial ligands $\left(\mathrm{X}=\mathrm{H}_{2} \mathrm{O}, \mathrm{CH}_{3} \mathrm{CN}\right)$ and spin states (singlet and triplet). Results are shown in Table S4 in the SI. Interestingly, although the singlet/triplet energy gap $\Delta \mathrm{E}_{\mathrm{S} / \mathrm{T}}$ value changes only slightly from the previously calculated one by complete structure optimization ( $6.2 \mathrm{vs.} 6.5 \mathrm{kcal} / \mathrm{mol}$ for $\mathrm{H}_{2} \mathrm{O}$ and $10.7 \mathrm{vs} .10 .2 \mathrm{kcal} / \mathrm{mol}$ for $\mathrm{CH}_{3} \mathrm{CN}$ ), the $\mathrm{Mn} 3 \mathrm{~d}_{\mathrm{xy}}-\pi^{*}(\mathrm{M}=\mathrm{O})$ energy difference in the singlet state does change significantly (1.31 vs. 1.16 $\mathrm{eV}$ for $\mathrm{H}_{2} \mathrm{O}$ and 1.30 vs. $1.14 \mathrm{eV}$ for $\mathrm{CH}_{3} \mathrm{CN}$; note that for $\mathrm{X}=$ none the value is $1.29 \mathrm{eV}$ ). These very close $\mathrm{Mn} 3 \mathrm{~d}_{\mathrm{xy}}-\pi^{*}(\mathrm{M}=\mathrm{O})$ energy difference values calculated for $\mathrm{X}=$ none, $\mathrm{H}_{2} \mathrm{O}$ and $\mathrm{CH}_{3} \mathrm{CN}$ in the singlet state suggest that they mainly account for porphyrin ruffling. Interestingly, the $\mathrm{Mn} 3 \mathrm{~d}_{\mathrm{xy}}-\pi^{*}$ $(\mathrm{M}=\mathrm{O})$ energy difference change from the fully optimized to the "ruffled" singlet for $\mathrm{H}_{2} \mathrm{O}$ and $\mathrm{CH}_{3} \mathrm{CN}$ is mainly due to the variation in the energy of the $\pi^{*}(\mathrm{M}=\mathrm{O})$ orbitals, which are now destabilized with respect to the fully optimized porphyrin conformation ( -8.10 vs. $-8.24 \mathrm{eV}$ for $\mathrm{H}_{2} \mathrm{O}$ and -7.80 vs. -8.00 $\mathrm{eV}$ for $\left.\mathrm{CH}_{3} \mathrm{CN}\right)$. On the contrary, the energy of the $\mathrm{Mn} 3 \mathrm{~d}_{\mathrm{xy}}$ orbital changes only slightly (-9.41 vs. $9.40 \mathrm{eV}$ for $\mathrm{H}_{2} \mathrm{O}$ and -9.10 vs. $-9.14 \mathrm{eV}$ for $\mathrm{CH}_{3} \mathrm{CN}$ ), indicating that they are more influenced by the axial ligand field effects. Thus, the porphyrin ruffling in the singlet state appears to mainly affect the energy of the $\pi^{*}(\mathrm{M}=\mathrm{O})$ orbitals, by pushing them up in energy $\left(\mathrm{X}=\right.$ none, $\pi^{*}$ energy $=-8.22 \mathrm{eV} ; \mathrm{X}=$ $\mathrm{H}_{2} \mathrm{O}, \pi^{*}$ energy $=-8.10 \mathrm{eV} ; \mathrm{X}=\mathrm{CH}_{3} \mathrm{CN}, \pi^{*}$ energy $=-7.80 \mathrm{eV}$ ). On this basis, we could expect that the "ruffled" triplet state arising from the promotion of one electron into the $\pi^{*}$ orbitals would be more destabilized for $\mathrm{CH}_{3} \mathrm{CN}$ than for $\mathrm{H}_{2} \mathrm{O}$, in agreement with the corresponding $\Delta \mathrm{E}_{\mathrm{S} / \mathrm{T}}$ values. Similar reactivity tuning by porphyrin ruffling distortion could be expected for $\mathrm{CN}^{-}, \mathrm{ClO}_{3}{ }^{-}, \mathrm{NO}_{3}{ }^{-}$and $\mathrm{NH}_{3}$ axial ligands, whose complexes show a nearly "flat" porphyrin conformation in the singlet state (RDA values in the range $0.3-6.6^{\circ}$ ) and a significantly ruffled one in the triplet (RDA values in the range $35.2-23.4^{\circ}$ ) (see Table S2). 
Our results show that, although the reactivity is mainly modulated by trans influence ligands, the porphyrin ruffling also finely tunes it, with $\mathrm{CH}_{3} \mathrm{CN}$ giving the lowest reactivity within the $\mathrm{X}=$ none, $\mathrm{H}_{2} \mathrm{O}, \mathrm{CH}_{3} \mathrm{CN}$ subset of comparable low trans influence ligands. These findings are corroborated by the spin density plots in the triplet state reported in Figure S8 in the SI for all the complexes. Only for $\mathrm{X}=\mathrm{Cl}^{-}, \mathrm{OH}^{-}$, and $\mathrm{O}^{2-}$ species spin density partially localizes on the axial ligand, whereas only for $\mathrm{X}=\mathrm{H}_{2} \mathrm{O}, \mathrm{CH}_{3} \mathrm{CN}$, and none partial spin density can be observed on the porphyrin moiety, interestingly located on the neuralgic points for the ligand ruffling folding.

In conclusion of this study, apart from the case of $\mathrm{O}^{2-}$, the singlet-triplet gap remains in the range of about $6-10 \mathrm{kcal} / \mathrm{mol}$, thus the Mn-porphyrin complexes are expected to be reactive intermediates in the different conditions provided by different axial ligands. We could surmise that the compound becomes unreactive only in the case of strongly basic ligands, such as $\mathrm{O}^{2-}$. Interestingly, we have found that the charge of the ligand tunes the ruffling distortion of the porphyrin and that in the triplet the porphyrin is always remarkably more ruffled than in the singlet spin state. The dianionic and strongly basic $\mathrm{O}^{2-}$ axial ligand shows a flat conformation of the porphyrin in both singlet and triplet states.

\section{A simplified model for Mn-porphyrin hydroxylation mechanism}

As we pointed out in the Introduction, there is an apparent conundrum because our calculations suggest that the $\mathrm{MnOP}$ are very reactive intermediates, with low reaction barriers, whereas the Newcomb experiments ${ }^{20}$ show that these complexes lead to very low yields in hydroxylation reactions, implying low rate constants and high reaction barriers. Basically the $\mathrm{Mn}(\mathrm{V})$ species, which are suggested to be the only one capable of high reactivity in catalytic conditions, are not highly concentrated, since they form Mn(IV) and Mn(III) intermediates that limit their amount. Thus, the measured rate constant could be apparent and lower than the real one.

This remark may clarify the incongruent result we found and will probably help to find new synthetic strategies to increase the experimental rate constant for the formation of oxidized products.

In order to have a quantitative idea of the agreement between our (and literature) theoretical studies and Newcomb kinetics ${ }^{20}$ we propose, in this section a comparison between the DFT computed reaction barrier and the experimental one, by means of a simplified reaction model.

In the reactivity section we found that the $\mathrm{MnOP}\left(\mathrm{H}_{2} \mathrm{O}\right)^{+}$complex reaction with the toluene substrate takes place via a first promotion from a low spin (singlet) to a high spin (triplet) state of the Mnporphyrin, that it is a thermal process $\left(\Delta \mathrm{E}_{\mathrm{S} / \mathrm{T}}^{\star}=6.5 \mathrm{kcal} / \mathrm{mol}\right)$ and a rapid reaction of the excited complex with the substrate, which has a very low energy barrier $\left(\Delta \mathrm{E}^{\dagger}\right.$ abstraction $\left.=0.5 \mathrm{kcal} / \mathrm{mol}\right)$, to form 
the final hydroxylated product occurs (Figure 1). Similar results were found by Eisenstein and coworkers $^{30}$ for $\left[\mathrm{MnO}(\mathrm{tHp})\left(\mathrm{H}_{2} \mathrm{O}\right)\right]^{+}\left(\Delta \mathrm{E}^{\ddagger} \mathrm{S} / \mathrm{T}=4.7 \mathrm{kcal} / \mathrm{mol}\right.$ and $\Delta \mathrm{E}^{\ddagger}$ abstraction $\left.=0.4 \mathrm{kcal} / \mathrm{mol}\right)$, $[\mathrm{MnO}(\mathrm{tHp})(\mathrm{OH})]\left(\Delta \mathrm{E}^{\dagger} \mathrm{s} / \mathrm{T}=9.2 \mathrm{kcal} / \mathrm{mol}\right.$ and $\Delta \mathrm{E}^{\ddagger}$ abstraction $\left.=4.3 \mathrm{kcal} / \mathrm{mol}\right)$, and $[\mathrm{MnO}(\mathrm{tHp})(\mathrm{O})]^{-}\left(\Delta \mathrm{E}^{\dagger} \mathrm{s} / \mathrm{T}\right.$ $=27.3 \mathrm{kcal} / \mathrm{mol}$ and $\Delta \mathrm{E}^{\ddagger}$ abstraction $\left.=8.0 \mathrm{kcal} / \mathrm{mol}\right)$. Although both $\Delta \mathrm{E}^{\ddagger}$ abstraction and $\Delta \mathrm{E}_{\mathrm{S} / \mathrm{T}}^{\dagger}$ values depend on the axial ligand, their relative values remain constant within each complex, where $\Delta \mathrm{E}^{\dagger}$ abstraction is always much smaller than $\Delta \mathrm{E}^{\dagger} \mathrm{S} / \mathrm{T}$.

These results are now summarized in Scheme 2.

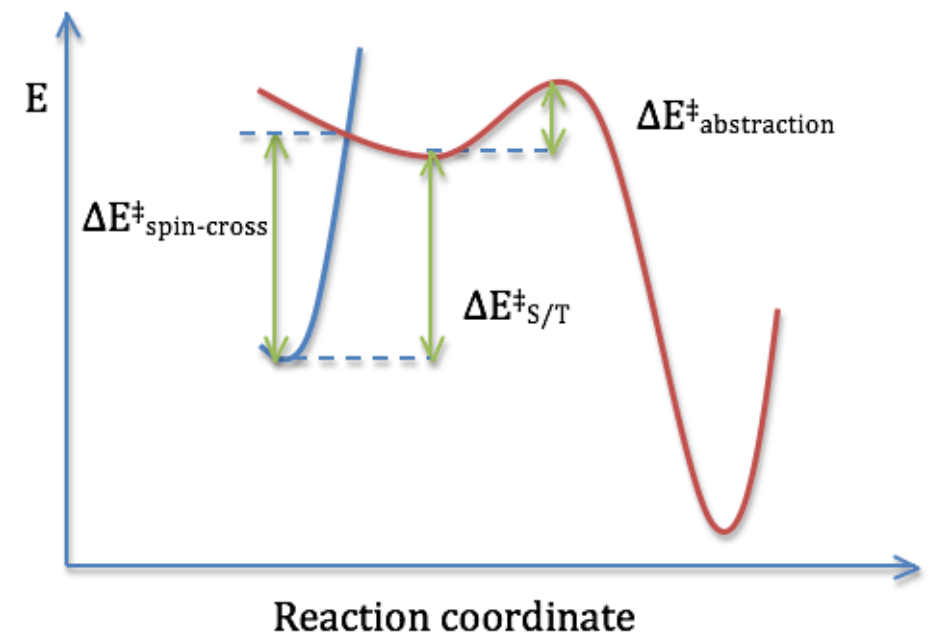

Scheme 2: Simplified scheme of the $\mathrm{MnOP}\left(\mathrm{H}_{2} \mathrm{O}\right)^{+}+$toluene $\mathrm{H}$-abstraction reaction

This reaction profile allows us to propose a simplified stepwise model for the reaction composed by a pre-equilibrium and a virtually barrier-less reaction. A first equilibrium between the singlet and the triplet $\mathrm{Mn}(\mathrm{V}) \mathrm{OP}$ complex (reac. 1) and a second irreversible reaction of the latter with toluene or other organic substrate (reac. 2) are defined as:

$$
\begin{array}{ll}
{ }^{1} \mathrm{MnOP} \rightleftharpoons{ }^{3} \mathrm{MnOP} & K=\frac{\left[{ }^{3} \mathrm{MnOP}\right]}{\left[{ }^{1} \mathrm{MnOP}\right]} \\
{ }^{3} \mathrm{MnOP}+\text { substrate } & { }_{2} \text { hydroxylatedproduct }
\end{array}
$$

We derive the kinetics law for the formation of the hydroxylated product $\mathrm{P}$ and we arrange the expression in terms of $\Delta \mathrm{G}^{\ddagger}$, free Gibbs energy barrier for reac. 2 , and $\Delta \mathrm{G}^{\circ}$, standard free Gibbs energy for the equilibrium in reac. $1 .{ }^{51}$ To this aim we use the Eyring formula as follows: 


$$
\begin{gathered}
\frac{d[P]}{d t}=k_{2} \cdot\left[{ }^{3} M n O P\right][\text { substrate }]=k_{2} \cdot K \cdot\left[{ }^{1} M n O P\right][\text { substrate }] \\
\frac{d[P]}{d t}=\frac{k K_{B} T}{h} \cdot \exp \left(\frac{-\Delta G^{\ddagger}}{R T}\right) \cdot \exp \left(\frac{-\Delta G^{\circ}}{R T}\right) \cdot\left[{ }^{1} M n O P\right][\text { substrate }] \\
\frac{d[P]}{d t}=\frac{k K_{B} T}{h} \cdot \exp \left(\frac{-\Delta G^{\ddagger}+\Delta G^{\circ}}{R T}\right) \cdot\left[{ }^{1} M n O P\right][\text { substrate }]
\end{gathered}
$$

This final expression suggests that, in such a case of pre-equilibrium, the observed activation Gibbs free energy is

$$
\Delta G_{\text {stepwise }}^{\ddagger}=\Delta G^{\circ}+\Delta G^{\ddagger}
$$

The first value of the sum, $\Delta \mathrm{G}^{\circ}$, could be computed by means of an analytical free energy calculation on the singlet and on the triplet optimized structures of $\mathrm{MnOP}\left(\mathrm{CH}_{3} \mathrm{CN}\right)^{+}$. Note that in order to take into account the solvation effects of acetonitrile, which is the solvent employed in the kinetics experiment, we replace the water axial ligand with the $\mathrm{CH}_{3} \mathrm{CN}$ molecule. This acts as a first-sphere micro-solvation for the complex. The optimized structures of $\mathrm{MnOP}\left(\mathrm{CH}_{3} \mathrm{CN}\right)^{+}$in the singlet and triplet state are depicted in Figure S9 in the SI. The $\Delta \mathrm{G}^{\circ}$ computed at $298.15 \mathrm{~K}$ amounts to 11.1 $\mathrm{kcal} / \mathrm{mol}$ (we recall that $\Delta \mathrm{E}=10.2 \mathrm{kcal} / \mathrm{mol}$, see Table $\mathrm{S} 1$ ).

The second value of the sum, $\Delta \mathrm{G}^{\ddagger}$, could be estimated as that arising from a bimolecular reaction occurring without a barrier, because the abstraction energy barrier is very small and hence its contribution to the free Gibbs energy is negligible. This kind of reaction should occur with a rate constant that is near the diffusion limit of $10^{9}-10^{10} \mathrm{M}^{-1} \mathrm{~s}^{-1}$, and thus such step should have an activation free energy at $300 \mathrm{~K}$ of about $4 \mathrm{kcal} / \mathrm{mol}^{20}{ }^{20}$, Hence, the theoretical value of $\Delta \mathrm{G}^{\ddagger}$ stepwise is about 15 $\mathrm{kcal} / \mathrm{mol}$.

In the kinetics studies performed by Newcomb and co-workers several different substrates for hydroxylation and epoxydation were employed and the measurements were all carried out at $295 \mathrm{~K}$ in acetonitrile. ${ }^{20}$

The rate constant of $\mathrm{Mn}(\mathrm{V}) \mathrm{OP}$ detected for the oxidation of the ethylbenzene substrate, the closest compound to toluene employed by us, was found to be $\mathrm{k}=(1.28 \pm 0.05) \times 10^{5} \mathrm{M}^{-1} \mathrm{~s}^{-1}$ at $295 \mathrm{~K}$. Using the Eyring equation, we obtain the value of $\Delta \mathrm{G}^{\ddagger}$ exp. 
$\Delta G_{\text {exp }}=-R \cdot T \cdot \log \left(\frac{k \cdot h}{k_{B} \cdot T}\right)=10.5 \mathrm{kcal} / \mathrm{mol}(10.4 \mathrm{kcal} / \mathrm{mol}$ at $295 \mathrm{~K})$

The theoretical and the experimental values of $\Delta \mathrm{G}^{+}$are in reasonable agreement with a difference of $4.6 \mathrm{kcal} / \mathrm{mol}$. The small energy difference between the two $\Delta G^{\ddagger}$ might arise mainly from the use of the BP86 functional that overestimates the singlet-triplet energy gap, and from the various assumptions we made in building the simplified model, first of all the absence of other species that are in the solution which have not been taken into account in our calculations (solvent molecules, basis, oxidizers, meso ligands, ....). In the context of this simplified stepwise reaction model, the three key aspects for the reactivity of MnOP species, namely spin-state crossing, equilibration of different oxidation states and $\mathrm{pH}$-effects, can be easily rationalized in terms of the pre-equilibrium reaction (reac. 1). The value of $\Delta G^{\circ}$ is evaluated as the singlet/triplet energy gap $\Delta E^{t_{\mathrm{S}} / \mathrm{T}}$ (spin-state crossing) whose value depends (among other factors) on pH-effects, as we have demonstrated in the axial ligand influence on reactivity analysis (see $\Delta \mathrm{E}^{+} \mathrm{S} / \mathrm{T}$ change along the $\mathrm{X}=\mathrm{H}_{2} \mathrm{O}, \mathrm{OH}^{-}$and $\mathrm{O}^{2-}$ series). In addition, the disproportionation equilibrium of $\mathrm{Mn}(\mathrm{IV})$ species is important in determining the concentrations of the active $\mathrm{Mn}(\mathrm{V})$ oxidant involved in reac.1. All of these three effects can thus control the reactivity through the pre-equilibrium step, particularly the $\mathrm{Mn}(\mathrm{III}) / \mathrm{Mn}(\mathrm{IV}) / \mathrm{Mn}(\mathrm{V})$ equlibria which may be responsible for the experimentally measured low product yields.

\section{Conclusions}

This work represents a theory/experiment reconciling study on the Mn-oxo porphyrins species reactivity for substrate hydroxylation. Kinetic and thermodynamic conclusions of MECP calculations on $\mathrm{H}$-abstraction from toluene by $\operatorname{MnOP}\left(\mathrm{H}_{2} \mathrm{O}\right)^{+}$have been deduced through deep investigations allowing to understand the reactivity. On the basis of MECP results, indicating a first crossover from a singlet spin state to a low-lying triplet spin state of the Mn-oxo porphyrin system, which represents the RDS with a thermally accessible barrier $(6.5 \mathrm{kcal} / \mathrm{mol})$, followed by a facile $\mathrm{H}$-abstraction by the triplet complex from the toluene substrate $\left(\Delta \mathrm{E}^{+}\right.$abstraction $\left.=0.5 \mathrm{kcal} / \mathrm{mol}\right)$, we investigated details of this reaction mechanism. The calculated high efficiency of the Mn-oxo porphyrins species for substrate oxidations even at thermal conditions is in sharp contrast with the experimental kinetic results by Newcomb and co-workers ${ }^{20}$ where low yields of hydroxylation have been observed which might suggest that the RDS energy barrier is on the contrary very high. To solve this conundrum, we specifically focused on the following different issues. A first issue we addressed is the accuracy of the level of theory employed by us in DFT computations for a correct description of the Mn-oxo- 
porphyrin system. We validated the singlet-triplet energy gap calculated for $\mathrm{MnOP}\left(\mathrm{H}_{2} \mathrm{O}\right)^{+}$using the BP86 functional vs. accurate DMRG-CASPT2/CC results. The comparison shows that the BP86 functional overestimates the gap only slightly (about $2 \mathrm{kcal} / \mathrm{mol}$ ), thus proving the reliability of our DFT results. A second issue concerns the influence of the axial ligand on $\mathrm{MnOP}\left(\mathrm{H}_{2} \mathrm{O}\right)^{+}$reactivity. Different experimental reaction conditions have been modeled by considering additional trans axial ligand, different from water, which can be present in the reaction environment. We find that the singlet-triplet energy gap ranges between 6.0 and $10.0 \mathrm{kcal} / \mathrm{mol}$ for $\mathrm{H}_{2} \mathrm{O}, \mathrm{OH}^{-}, \mathrm{CH}_{3} \mathrm{CN}, \mathrm{Cl}^{-}$and none, suggesting that it is not much affected by such axial ligands, except in the case of very basic species (like $\mathrm{O}^{2-}$ ) for which the singlet-triplet energy gap is largely increased (about $28 \mathrm{kcal} / \mathrm{mol}$ ). The widening of the singlet-triplet energy gaps can be ascribed to the increasing trans influence, which mainly controls the reactivity. Yet another factor could finely tune the singlet-triplet energy gap, which is the porphyrin ruffling distortion. Finally, relying on our findings, a stepwise model for the $\mathrm{H}$-abstraction process is proposed, where a first equilibrium between the singlet and triplet $\mathrm{MnOP}\left(\mathrm{CH}_{3} \mathrm{CN}\right)^{+}$occurs and successively the triplet $\mathrm{MnOP}\left(\mathrm{CH}_{3} \mathrm{CN}\right)^{+}$reacts with toluene under diffusion control (the reaction is virtually barrier-less). This reaction model allowed a final comparison with the high resolution experimental kinetic study by Newcomb and co-workers ${ }^{20}$ where the active $\mathrm{Mn}(\mathrm{V}) \mathrm{OPs}$ are generated directly by laser flash photolysis. The agreement with experiment is surprisingly good: a theoretical free activation energy of $15.1 \mathrm{kcal} / \mathrm{mol}$ was calculated vs an experimental value of $10.5 \mathrm{kcal} / \mathrm{mol}$. Furthermore, Newcomb and co-workers in their work suggested that the apparent low yields of hydroxylation are due to the fact that a small amount of Mn(V)OPs remains in the solution because of comproportionation and disproportionation equilibria giving Mn(IV)OPs and Mn(III)OPs, which have far less oxidation power. Our final result could be thought, within the restriction of the considered model, as a confirmation that such equilibria may be responsible for the low yields measured and, hence, could represent a starting point for future new investigations, both theoretical and experimental, aimed at improving the Mn-oxo porphyrin catalytic efficiency through variation of solution conditions.

\section{Acknowledgements}


D.R., L.B. and P.B. gratefully acknowledge financial support from MIUR and the University of Perugia to the project AMIS, through the program "Dipartimenti di Eccellenza - 2018-2022". QMP thanks funding from KU Leuven Postdoctoral mandates (PDM/16/112).

\section{Conflict of interest}

The authors declare no conflict of interest.

\section{Keywords:}

Mn-oxo porphyrins reactivity, hydroxylation reaction, density functional theory, minimum energy crossing point, DMRG-CASPT2/CC calculations

\section{References}

1 Shimazaki, Y.; Nagano, T.; Takesue, H.; Ye, B.-H. ; Tani, F.; Naruta, Y. Characterization of a dinuclear $\mathrm{Mn}^{\mathrm{V}}=\mathrm{O}$ complex and its efficient evolution of $\mathrm{O}_{2}$ in the presence of water. Angew. Chem. Int. Ed. 2004, 43, 98-100.

2 Rose, E.; Andrioletti, B.; Zrig, S.; Quelquejeu-Ethève, M. Enantioselective epoxidation of olefins with chiral metalloporphyrin catalysts. Chem. Soc. Rev. 2005, 34, 573-583.

3 Park, S.-E. ; Song, W.J.; Ryu, Y.O.; Lim, M.H.; Song, R.; Kim, K.M.; Nam, W. Parallel mechanistic studies on the counterion effect of manganese salen and porphyrin complexes on olefin epoxidation by iodosylarenes. J. Inorg. Biochem. 2005, 99, 424-431.

4 Borovik, A.S. Role of metal-oxo complexes in the cleavage of C-H bonds. Chem. Soc. Rev. 2011, 40, 1870-1874. 
5 Collman, J.P.; Zeng, L.; Wang, H.J.H.; Lei, A.; Brauman, J.I. Kinetics of (porphyrin)manganese(III)catalyzed olefin epoxidation with a soluble iodosylbenzene derivative. Eur. J. Org. Chem. 2006, 2707-2714.

$6 \quad$ Srour, H.; Le Maux, P.; Simonneaux, G. Enantioselective manganese-porphyrin-catalyzed epoxidation and $\mathrm{C}-\mathrm{H}$ hydroxylation with hydrogen peroxide in water/methanol solutions. Inorg. Chem. 2012, $51,5850-5856$.

$7 \quad$ Elemans, J.A.A.W. ; Bijsterveld, E.J.A.; Rowan, A.E.; Nolte, R.J.M. Manganese porphyrin hosts as epoxidation catalysts - Activity and stability control by axial ligand effects. Eur. J. Org. Chem. 2007, 751-757.

8 Santos da Silva, V.; Idemori, Y.M.; DeFreitas-Silva, G. Biomimetic alkane oxidation by iodosylbenzene and iodobenzene diacetate catalyzed by a new manganese porphyrin: water effect. Appl. Catal. A: General 2015, 498, 54-62.

$9 \quad$ Hull, J.F.; Sauer, E.L.O.; Incarvito, C.D.; Faller, J.W.; Brudvig, G.W.; Crabtree, R.H. Manganese catalysts with molecular recognition functionality for selective alkene epoxidation. Inorg. Chem. 2009, 48, 488-495.

10 Liu, H.-Y. ; Yam, F.; Xie, Y.-T.; Li, X.-Y.; Chang, C.K. A bulky bis-pocket manganese(V)-oxo corrole complex: observation of oxygen atom transfer between triply bonded $\mathrm{Mn} \mathrm{V}^{\mathrm{V}} \equiv \mathrm{O}$ and alkene. J. Am. Chem. Soc. 2009, 131, 12890-12891.

11 Jin, N.; Lahaye, D.E.; Groves, J.T. A "push-pull" mechanism for heterolytic O-O bond cleavage in hydroperoxo manganese porphyrins. Inorg. Chem. 2010, 49, 11516-11524.

12 Hull, J.F.; Balcells, D.; Sauer, E.L.O.; Raynaud, C.; Brudvig, G.W.; Crabtree, R.H.; Eisenstein, O. Manganese catalysts for $\mathrm{C}-\mathrm{H}$ activation: an experimental/theoretical study identifies the stereoelectronic factor that controls the switch between hydroxylation and desaturation pathways. J. Am. Chem. Soc. 2010, 132, 7605-7616.

13 a) Groves, J.T.; Stern, M.K. Synthesis, characterization, and reactivity of oxomanganese (IV) porphyrin complexes. J. Am. Chem. Soc. 1988, 110, 8628-8638; b) Spiro, T.G.; Czernuszewicz, R.S.; Li, X.-Y. Metalloporphyrin structure and dynamics from resonance raman spectroscopy. Coord. Chem. Rev. 1990, 100, 541-571; c) Mansuy, D. Activation of alkanes: the biomimetic approach. Coord. Chem. Rev. 1993, 125, 129-141.

14 a) Meunier, B.; Bernadou, J. Metal-oxo species in P450 enzymes and biomimetic models. Oxohydroxo tautomerism with water-soluble metalloporphyrins. Top. Catal. 2002, 21, 47-54; b) Metalloporphyrins in Catalytic Oxidations, (Ed: R.A. Sheldon ), Marcel Dekkers, Inc., 1994.

15 Groves, J.T.; Lee, J.; Marla, S.S. Detection and characterization of an oxomanganese(V) porphyrin complex by rapid-mixing stopped-flow spectrophotometry. J. Am. Chem. Soc. 1997, 119, 6269-6273.

16 Jin, N.; Groves, J.T. Unusual kinetic stability of a ground-state singlet oxomanganese(V) porphyrin. Evidence for a spin state crossing effect. J. Am. Chem. Soc. 1999, 121, 2923-2924.

17 Nam, W.; Kim, I.; Lim, M.H.; Choi, H.J.; Lee, J.S.; Jang, H.G. Isolation of an oxomanganese(V) porphyrin intermediate in the reaction of a manganese(III) porphyrin complex and $\mathrm{H}_{2} \mathrm{O}_{2}$ in aqueous solution. Chem. Eur. J. 2002, 8, 2067-2071. 
Song, W.J.; Seo, M.S.; DeBeer George, S.; Ohta, T.; Song, R.; Kang, M.-J.; Tosha, T.; Kitagawa, T.; Solomon, E.I.; Nam, W. Synthesis, characterization, and reactivities of manganese(V)-oxo porphyrin complexes. J. Am. Chem. Soc. 2007, 129, 1268-1277.

19 Zhang, R.; Newcomb, M. Laser flash photolysis formation and direct kinetic studies of manganese(V)-oxo porphyrin intermediates. J. Am. Chem. Soc. 2003, 125, 12418-12419.

20 Zhang, R.; Horner, J.H.; Newcomb, M. Laser flash photolysis generation and kinetic studies of porphyrin-manganese-oxo intermediates. Rate constants for oxidations effected by porphyrin-Mn $\mathrm{M}^{\mathrm{V}}$-oxo species and apparent disproportionation equilibrium constants for porphyrin- $\mathrm{Mn}^{\mathrm{IV}}$-oxo species. J. Am. Chem. Soc. 2005, 127, 6573-6582.

21 Schröder, D.; Shaik, S.; Schwarz, H. Two-state reactivity as a new concept in organometallic chemistry. Acc. Chem. Res. 2000, 33, 139-145.

23 Jin, N.; Ibrahim, M.; Spiro, T.G.; Groves, J.T. Trans-dioxo manganese(V) porphyrins. J. Am. Chem. Soc. 2007, 129, 12416-12417.

24 Groves, J.T. Key elements of the chemistry of cytochrome P-450: the oxygen rebound mechanism. J. Chem. Educ. 1985, 62, 928-931.

25 Groves, J.T. Reactivity and mechanisms of metalloporphyrin-catalyzed oxidations. J. Porphyrins Phthalocyanines 2000, 4, 350-352.

26 Slaughter, L.M.; Collman, J.P.; Eberspacher, T.A.; Brauman, J.I. Radical autoxidation and autogenous $\mathrm{O}_{2}$ evolution in manganese-porphyrin catalyzed alkane oxidations with chlorite. Inorg. Chem. 2004, 43, 5198-5204.

27 Balcells, D.; Raynaud, C.; Crabtree, R.H.; Eisenstein, O. The rebound mechanism in catalytic C-H oxidation by $\mathrm{MnO}(\mathrm{tpp}) \mathrm{Cl}$ from DFT studies: electronic nature of the active species. Chem. Commun. 2008, 744-746.

28 Venturinelli Jannuzzi, S.A.; Phung, Q.M.; Domingo, A.; Barboza Formiga, A.L.; Pierloot, K. Spin state energetics and oxyl character of Mn-oxo porphyrins by multiconfigurational ab initio calculations: implications on reactivity. Inorg. Chem. 2016, 55, 5168-5179.

29 De Angelis, F. ; Jin, N. ; Car, R. ; Groves, J.T. Electronic structure and reactivity of isomeric oxo$\mathrm{Mn}(\mathrm{V})$ porphyrins : effects of spin-state crossing and $\mathrm{pK}_{\mathrm{a}}$ modulation. Inorg. Chem. 2006, 45, 4268-4276.

30 Balcells, D.; Raynaud, C.; Crabtree, R.H.; Eisenstein, O. A rational basis for the axial ligand effect in $\mathrm{C}-\mathrm{H}$ oxidation by $[\mathrm{MnO} \text { (porphyrin) }(\mathrm{X})]^{+}\left(\mathrm{X}=\mathrm{H}_{2} \mathrm{O}, \mathrm{OH}^{-}, \mathrm{O}^{2-}\right)$ from a DFT study. Inorg. Chem. 2008, 47, 1009010099.

31 Phung, Q.M.; Feldt, M.; Harvey, J.N.; Pierloot, K. Toward highly accurate spin state energetics in first-row transition metal complexes: a combined CASPT2/CC approach. J. Chem. Theory Comput. 2018, 14, 2446-2455.

32 a) Ghosh, A.; Persson, B.J.; Taylor, P.R. Ab initio multiconfiguration reference perturbation theory calculations on the energetics of low-energy spin states of iron(III) porphyrins. J. Biol. Inorg. Chem. 2003, 8, 507-511; b) Ghosh, A.; Taylor, P.R. High-level ab initio calculations on the energetics of low-lying spin states 26 
of biologically relevant transition metal complexes: a first progress report. Curr. Opin. Chem. Biol. 2003, 7, 113-124; c) Radoń, M. Spin-state energetics of heme-related models from DFT and Coupled Cluster calculations. J. Chem. Theory Comput. 2014, 10, 2306-2321; d) Vancoillie, S.; Zhao, H.; Radoń, M.; Pierloot, K. Performance of CASPT2 and DFT for relative spin-state energetics of heme models. J. Chem. Theory Comput. 2010, 6, 576-582.

33 a) Fonseca Guerra, C.; Snijders, J.G.; te Velde, G.; Baerends, E.J. Towards an order-N DFT method. Theor. Chem. Acc. 1998, 99, 391-403; b) ADF2014.04, SCM, Theoretical Chemistry, Vrije Universiteit, Amsterdam, The Netherlands, http://www.scm.com.

34 a) Becke, A.D. Density-functional exchange-energy approximation with correct asymptotic behavior. Phys. Rev. A 1988, 38, 3098-3100; b) Perdew, J.P.; Wang, Y. Accurate and simple density functional for the electronic exchange energy: generalized gradient approximation. Phys. Rev. B 1986, 33, 8800-8802; Erratum: Accurate and simple density functional for the electronic exchange energy: generalized gradient approximation. Phys. Rev. B 1989, 40, 3399.

35 Grimme, S.; Ehrlich, S.; Goerigk, L. Effect of the dumping function in dispersion corrected density functional theory. J. Comput.Chem. 2011, 32, 1456-1465.

36 a) van Lenthe, E.; Baerends, E.J.; Snijders, J.G. Relativistic total energy using regular approximations. J. Chem. Phys. 1994, 101, 9783-9792; b) van Lenthe, E.; Ehlers, A.; Baerends, E.J. Geometry optimizations in the zero order regular approximation for relativistic effects. J. Chem. Phys. 1999, 110, 8943-8953; c) van Lenthe, E.; van Leeuwen, R.; Baerends, E.J.; Snijders, J.G. Relativistic regular twocomponent Hamiltonians. Int. J. Quantum Chem. 1996, 57, 281-293; d) van Lenthe, E.; Snijders, J.G.; Baerends, E.J. The zero-order regular approximation for relativistic effects: the effect of spin-orbit coupling in closed shell molecules. J. Chem. Phys. 1996, 105, 6505-6516.

37 Harvey, J.N.; Aschi, M.; Schwarz, H.; Koch, W. The singlet and triplet states of phenyl cation. A hybrid approach for locating minimum energy crossing points between non-interacting potential energy surfaces. Theor. Chem. Acc. 1998, 99, 95-99.

38 Wouters, S.; Poelmans, W.; Ayers, P.W.; Van Neck, D. CheMPS2: a free open-source spin-adapted implementation of the density matrix renormalization group for ab initio quantum chemistry. Comp. Phys. Comm. 2014, 185, 1501-1514.

39 Aquilante, F.; Autschbach, J.; Carlson, R.K.; Chibotaru, L.F.; Delcey, M.G.; De Vico, L.; Galván, I.F.; Ferré, N.; Frutos, L.M.; Gagliardi, L.; Garavelli, M.; Giussani, A.; Hoyer, C.E.; Li Manni, G.; Lischka, H.; Ma, D.; Malmqvist, P.-Å. ;Müller, T.; Nenov, A.; Olivucci, M.; Pedersen, T.B.; Peng, D.; Plasser, F.; Pritchard, B.; Reiher, M.; Rivalta, I.; Schapiro, I.; Segarra-Martí, J.; Stenrup, M.; Truhlar, D.G.; Ungur, L.; Valentini, A.; Vancoillie, S.; Veryazov, V.; Vysotskiy, V.P.; Weingart, O.; Zapata, F.; Lindh, R. MOLCAS 8: new capabilities for multiconfigurational quantum chemical calculations across the periodic table. J. Comp. Chem. 2016, 37, 506-541.

40 Roos, B.O.; Lindh, R.; Malmqvist, P.-Å.; Veryazov, V.; Widmark, P.-O. New relativistic ANO basis sets for transition metal atoms. J. Phys. Chem. A 2005, 109, 6575-6579.

$41 \quad$ Roos, B.O.; Lindh, R.; Malmqvist, P.-Å.; Veryazov, V.; Widmark, P.-O. Main group atoms and dimers studied with a new relativistic ANO basis set. J. Phys. Chem. A 2004, 108, 2851-2858. 
Widmark, P.-O.; Malmqvist, P.-Å.; Roos, B.O. Density matrix averaged atomic natural orbital (ANO) basis sets for correlated molecular wave functions. Theor. Chem. Acc. 1990, 77, 291-306.

43 Aquilante, F.; Malmqvist, P.-Å.; Pedersen, T.B.; Ghosh, A.; Roos, B.O. Cholesky decomposition-based multiconfiguration second-order perturbation theory (CD-CASPT2): application to the spin-state energetics of Co'"(diiminato)(NPh). J. Chem. Theory Comp. 2008, 4, 694-702.

44 a) Hess, B.A. Relativistic electronic-structure calculations employing a two-component no-pair formalism with external-field projection operators. Phys. Rev. A 1986, 33, 3742-3748; b) Reiher, M.; Wolf, A. Exact decoupling of the Dirac Hamiltonian. I. General theory. J. Chem. Phys. 2004, 121, 2037-2047; c) Reiher, M.; Wolf, A. Exact decoupling of the Dirac Hamiltonian. II. The generalized Douglas-Kroll-Hess transformation up to arbitrary order. J. Chem. Phys. 2004, 121, 10945-10956.

45 Ghigo, G.; Roos, B.O.; Malmqvist, P.-Å. A modified definition of the zeroth-order Hamiltonian in multiconfigurational perturbation theory (CASPT2). Chem. Phys. Lett. 2004, 396, 142-149.

46 Forsberg, N.; Malmqvist, P.-Å. Multiconfiguration perturbation theory with imaginary level shift. Chem. Phys. Lett. 1997, 274, 196-204.

47 a) Werner, H.-J.; Knowles, P.J.; Knizia, G.; Manby, F.R.; Schütz, M. Molpro: a general-purpose quantum chemistry program package. WIRES Comput. Mol. Sci. 2012, 2, 242-253; b) Werner, H.-J. ; Knowles, P.J.; Knizia, G.; Manby, F.R.; Schütz, M.; Celani, P.; Korona, T.; Lindh, R.; Mitrushenkov, A.; Rauhut, G.; Shamasundar, K.R.; Adler, T.B.; Amos, R.D.; Bernhardsson, A.; Berning, A.; Cooper, D.L.; Deegan, M.J.O.; Dobbyn, A.J.; Eckert, F.; Goll, E.; Hampel, C.; Hesselmann, A.; Hetzer, G.; Hrenar, T.; Jansen, G.; Köppl, C.; Liu, Y.; Lloyd, A.W.; Mata, R.A.; May, A.J.; McNicholas, S.J.; Meyer, W.; Mura, M.E.; Nicklass, A.; O’Neill, D.P.; Palmieri, P.; Peng, D.; Pflüger, K.; Pitzer, R.; Rehier, M.; Shiozaki, T.; Stoll, H.; Stone, A.J.; Tarroni, R.; Thorsteinsson, T.; Wang, M. MOLPRO, version 2012.1, a package of ab initio programs, Cardiff, UK, http://www.molpro.net

48 Peterson, K.A.; Puzzarini, C. Systematically convergent basis sets for transition metals. II. Pseudopotential-based correlation consistent basis sets for the group $11(\mathrm{Cu}, \mathrm{Ag}, \mathrm{Au})$ and $12(\mathrm{Zn}, \mathrm{Cd}, \mathrm{Hg})$ elements. Theor. Chem. Acc. 2005, 114, 283-296.

49 Janowski, T. Near equivalence of intrinsic atomic orbitals and quasiatomic orbitals. J. Chem. Theory Comp. 2014, 10, 3085-3091.

50 Imada, Y.; Nakamura, H.; Takano, Y. Density functional study of porphyrin distortion effects on redox potential of heme. J. Comput. Chem. 2018, 39, 143-150.

51 Seeman, J.I. The Curtin-Hammett principle and the Winstein-Holness equation. New definition and recent extensions to classical concepts. J. Chem. Ed. 1986, 63, 42-48.

52 McMullin, C.L.; Jover, J.; Harvey, J.N.; Fey, N. Accurate modelling of Pd(0) + PhX oxidative addition kinetics. Dalton Trans. 2010, 39, 10833-10836. 
TOC

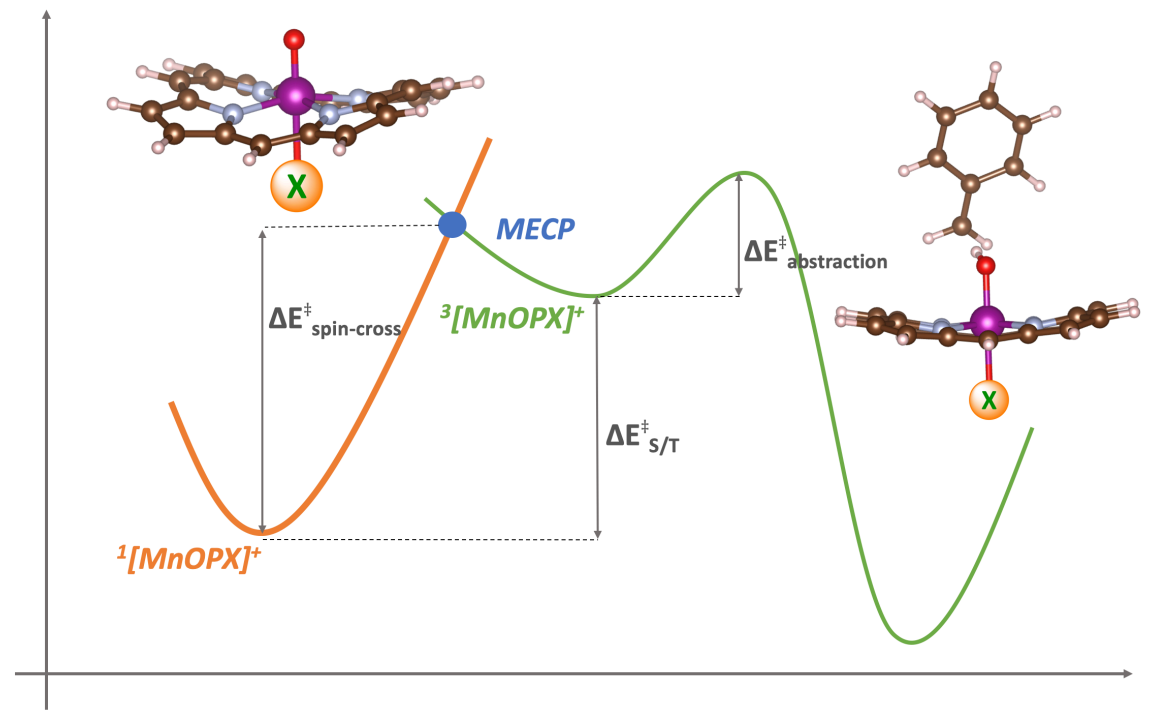

Synopsis: Theoretical studies predict $\mathrm{Mn}(\mathrm{V})$-oxo porphyrin species as very reactive intermediates in hydroxylation reactions with thermally accessible activation barriers represented by low spin/high spin crossover. On the other hand, experimental evidence for very low yields in such reactions has been provided. A stepwise model for the $\mathrm{H}$-abstraction process is proposed which reconciles theory and experiment and allows to understand the reactivity of the Mn-oxo porphyrins. 